\title{
A COST-BENEFIT ANALYSIS MODEL FOR THE RETROFIT OF SUSTAINABLE URBAN DRAINAGE SYSTEMS TOWARDS IMPROVED FLOOD RISK MITIGATION
}

\begin{tabular}{|r|l|}
\hline Journal: & International Journal of Building Pathology and Adaptation \\
\hline Manuscript ID & IJBPA-12-2018-0105.R2 \\
\hline Manuscript Type: & Original Article \\
\hline Keywords: & $\begin{array}{l}\text { Flood risk, Commercial properties, Conceptual framework, Costs, } \\
\text { Benefits }\end{array}$ \\
\hline \multicolumn{2}{l}{} \\
\hline
\end{tabular}


A COST BENEFIT ANALYSIS MODEL FOR THE RETROFIT OF SUSTAINABLE URBAN DRAINAGE SYSTEMS TOWARDS IMPROVED FLOOD RISK MITIGATION

\begin{tabular}{|c|c|}
\hline Purpose of this paper & $\begin{array}{l}\text { The Environment Agency estimates that one } \\
\text { in six homes in England (approximately } \\
5.2 \text { million properties) are at risk from } \\
\text { flooding and } 185,000 \text { commercial properties } \\
\text { are located in flood prone areas. Further, an } \\
\text { estimated 10,000 new homes are built on } \\
\text { flood plains yearly. The UK has witnessed a } \\
\text { significant increase in flood events over the } \\
\text { past } 10 \text { years. During this period, there has } \\
\text { been growing research attention into } \\
\text { measures to mitigate the effects of flooding, } \\
\text { including the benefits of deploying } \\
\text { Sustainable Urban Drainage Systems (SuDs) } \\
\text { in new developments or as a retrofit. This } \\
\text { study presents the development of a cost- } \\
\text { benefit analysis model for the retrofit of } \\
\text { SuDs focusing on the potential for improved } \\
\text { flood risk mitigation in the context of } \\
\text { commercial properties. }\end{array}$ \\
\hline Design/methodology/approach & $\begin{array}{l}\text { A synthesis of the flood risk management } \\
\text { and SuDs literature is used to inform the } \\
\text { development of a conceptual cost-benefit } \\
\text { analysis model for the retrofit of SuDs and } \\
\text { focusing on the potential for improved flood } \\
\text { risk mitigation in the context of commercial } \\
\text { properties. }\end{array}$ \\
\hline Findings (mandatory) & $\begin{array}{l}\text { Sustainable urban drainage systems have } \\
\text { been applied successfully in different parts }\end{array}$ \\
\hline
\end{tabular}




\begin{tabular}{|c|c|}
\hline & $\begin{array}{l}\text { of the world, however, the uptake of SuDs, } \\
\text { in particular the retrofit of SuDs, has been } \\
\text { restricted by a number of issues including a } \\
\text { lack of experience and trust in their } \\
\text { performance and a lack of understanding in } \\
\text { their true benefits. In particular, there is } \\
\text { limited experience of retrofitting SuDs and } \\
\text { there are no well established procedures for } \\
\text { evaluating the feasibility, value or cost- } \\
\text { effectiveness of doing this. }\end{array}$ \\
\hline Social implications & $\begin{array}{l}\text { This offers the potential to support the UK } \\
\text { government's flood risk management policy } \\
\text { by helping to increase the resilience of } \\
\text { properties, whilst offering other benefits to } \\
\text { communities such as improvements in air } \\
\text { quality and biodiversity and also presenting } \\
\text { a clearer understanding of the monetary and } \\
\text { non-monetary implication to owners of } \\
\text { commercial properties for a more informed } \\
\text { and acceptable uptake of SuDs retrofit. }\end{array}$ \\
\hline Originality/value (mandatory & $\begin{array}{l}\text { The proposed model will allow a more } \\
\text { comprehensive understanding of the costs } \\
\text { and associated benefits associated with } \\
\text { SuDs retrofit, highlighting the flood risk } \\
\text { mitigation benefits that might accrue over a } \\
\text { period of time for commercial property. }\end{array}$ \\
\hline
\end{tabular}

Keywords: Flood risk, Commercial properties, Conceptual framework, Costs, Benefits. 


\subsection{INTRODUCTION}

Globally, more than $80 \%$ of the population living on land are prone to flooding (Winsemius, et al., 2018). In 2007, the worst flooding experience in the UK since 1947 coincided with the start of the worst financial crisis since the 1930s. These had a major impact on people, properties and businesses and brought the need for a better risk management system. In the UK, the environment agency estimates that one in six homes in England (approximately 5.2million properties) are at risk from flooding. Included in this statistics is an average of 10,000 homes which are built on flood plains yearly, while 185,000 commercial properties are located in flood prone areas. These properties are valued at over $£ 801$ billion which accounts for 15.8 per cent of the value of total buildings and 2.2 per cent of total assets in the UK (Bhattacharya, et al., 2013). One in six residential and commercial properties, which form about 2.4 million in England are at risk of flooding from main rivers or the sea.

The commercial property sector plays an important role in the UK economy, both as a direct or indirect employer, a generator of output, and in providing other sectors including retailers, financial and business services, with a critical factor of production, that is, the location from which their business is done. It is estimated that the total output in the sector in 2011 was around $f 41 \mathrm{bn}$ which is equivalent to $3.2 \%$ of UK gross value added (GVA) and total employment of over 800,000 . The sector makes a substantial contribution to the exchequer, with an estimated contribution in VAT and PAYE income tax of approximately $f 6.5 \mathrm{bn}$. Any disruption to the activities in this sector would be detrimental to the growth of the UK economy in total.

Sustainable Urban Drainage Systems (SuDs) are a system which could be used to protect commercial properties from flooding. SuDs are uniquely designed to mimic natural infiltration patterns, so that they can reduce the risk of flooding by reducing runoff volume and attenuation peak flows. Kirby (2005) described SuDs as more sustainable than conventional drainage methods because they are designed to manage flow rates, protect or enhance water quality and are sympathetic to the environmental setting and the needs of the local community by dealing with runoff close to where rain falls or attenuating flows and controlling discharges downstream.

However, the uptake of SuDs and the retrofit of SuDs has been restricted by a number of issues including, a lack of experience and trust in such schemes, and a lack of understanding of their 
wider benefits (Oladunjoye, et al., 2017; Malulu, 2016; Ossa-Moreno, 2017; Ellis, 2013; Lamond, 2016). There has been limited research on the retrofit of SuDs and there are no well established procedures for evaluating the feasibility, value or cost-effectiveness of doing this (Ossa-Moreno, 2017 and Alexander, et al., 2016). Lead (2018) revealed that 68\% of construction professionals felt there was a lack of understanding of SuDs among key decisionmakers. However, there remains growing interest in the introduction of this technology (Stovin, 2010) and stakeholders and researchers have sought to develop modalities on how to make SuDs more acceptable and relevant in the UK (Carboni, 2016). This study aims to help facilitate a deeper appreciation of the monetary and non-monetary value of SuDs retrofit with the development of a cost benefit analysis (CBA) model towards improving uptake and thereby improving flood risk mitigation in commercial properties in the UK. The results of this study will help to develop a better understanding of the long term viability of SuDs retrofit and its monetary value, in order to encourage uptake by key decision makers involved in the development and redevelopment of buildings.

\subsection{SUSTAINABLE URBAN DRAINAGE SYSTEMS}

Sustainable urban drainage systems (SuDs) is a generic term that refers to various measures used to control the effect of surface water runoff in the environment (Locatelli, 2016). Booth and Charlesworth (2017) defined sustainable drainage as the management of rainwater which includes snow and other precipitation, with the aim of reducing damages caused by flooding events, improving the quality of water, the improvement and protection of the environment, the improvement and safety of the health of the residents and the process of ensuring the effective stability and durability of drainage systems. Baron and Petersen (2016) further described SuDs as an important contribution to urban climate change adaptation.

SuDs replicate the natural drainage processes of an area through the use of vegetation-based interventions such as swales, water gardens, and green roofs, which increase localised infiltration, attenuation and/or detention of stormwater. Hence, SuDs improves flood alleviation capacity in any community. SuDs are essential for the reduction in the quantity of surface water that flows off a surface and are useful for different purposes including reduction in runoff by, for example, the installation of green roofs or other SuDs which could result in savings in wastewater disposal (Wilkinson, and Dixon, 2016). The most well used SuDs are rainwater harvesting systems, green roofs, swales, rainwater beds and permeable surfaces as 
well as open drainage waterways and reservoirs for excess rainwater (Baron and Petersen, 2016). All these solutions aim to absorb, evaporate and/or channel rainwater so it does not end up in the sewage system.

\subsection{Retrofit of Sustainable Urban Drainage Systems}

SuDs retrofit is a storm water management process which is aimed at addressing urban water quality and the problems associated with flooding (Walsh, et al, 2016). Retrofit is used when SuDs are proposed for the replacement or augmentation of an existing drainage system (Smith, 2016). Examples of retrofitting SuDs can be seen in the installation of green roofs, the diversion of roof drainage from a combined sewer system into a garden soakaway, and the conveyance of road runoff via roadside swales into a pond sited in an area of open space (Ellis, 2013). These represent alternative ways of influencing the quality of the water downstream and the problems relating to it, thereby providing a more effective, resilient and sustainable approach. For SuDs to be acceptable, three core attributes are essential: economic viability, resilience and sustainability (Lead, 2018).

In considering the economic viability of SuDs retrofit, it is important that SuDs retrofit is affordable in costs and benefit for it to be accepted as a potential replacement for the existing drainage system. Fisher-Jeffes et al. (2011) identified that impacts such has aesthetics, economic value, rainwater harvesting, influences the choices made by individuals and organisations as it affects the cost and sale of properties. Ossa-Moreno et al. (2017) opined that for a SuDs retrofit installation to be economically feasible or viable, the wider benefits would need to be taken into account.

Resilience is multifaceted and is defined in different ways by various professionals. Proverbs et al., (2018) defines resilience as the ability of a system to return to its stable state after a momentary disturbance. Therefore, the acceptance of SuDs retrofit in terms of its resilience requires that the installation of SuDs retrofit would help to restore any flood affected area into a more attractive place.

According to Sieker et al. (2008), SuDs are known to be more adaptable and flexible than traditional solutions, allowing future modification to cope with climate and other changes in urban areas. Therefore, if SuDs retrofit can be incorporated into existing developed areas, the opportunities for delivering sustainable solutions that offer multiple benefits will be much greater. 


\subsection{The Implementation of the Retrofit of SuDs}

In this section, various benefits and barriers to the uptake of SuDs retrofit have been identified. The implication of the impact of these factors are further discussed.

\section{Processes of the implementation of the retrofit of SuDs}

A number of benefits that cut across various positive improvements in schemes and the lives of people have been identified. For example, Malulu (2016) found that a common SuDs intervention scheme entails the carrying out of works to rivers with the aim of increasing their capacity to carry flood flows. Friberg et al. (2016) identify a further scheme involving channel maintenance or enlarging the channel cross section and thereby increasing the flow of surface water by extending the capacity. The mitigation of the heat island effect and noise, the improvement in air and water quality and the provision of sites for recreation or urban amenities are various ways by which the ecosystem is sustained through SUDS retrofit (Demuzere et al., 2014; Ellis, 2013; Kazmierczak et al., 2010).

Other benefits of SuDs retrofit is in the reduced cost of infrastructure by the introduction of green infrastructure. Ellis (2013) argues that conventional drainage systems cannot provide the expected solution to any flood mitigation process but an extended approach based on the introduction of retrofit SuDs, in the likes of micro-and meso-vegetative SuDS systems into a wider green infrastructure(GI) framework, can effectively address on-site and catchment urban surface water issues. Foster et al. (2011), identified the importance of the aesthetic value of a building or location which is increased by the installation of SuDs retrofit by way of green infrastructure, creating habitat for wildlife, by constructing swales and other forms.

Health improvements from the use of SuDs is also an important benefit to every citizen. Lamond et al. (2015) affirm the importance of an improved flood risk management system to manage the growing pressure of the effect of flooding events on the health of the occupants of any community. Greenough et al. (2001) address the health effects of flooding which are typically associated with disasters. These are direct morbidity and mortality and secondary or indirect health impacts. A direct impact includes an impaired public health infrastructure, reduced access to health care facilities, and psychological and social effects. While indirect effects could result in the alteration of ecologic systems which may result in land covers (i.e, grass, asphalt, trees etc) being damaged, and the abundance and distribution of disease- 
carrying insects, rodents and some other vectors. An improved health system through the application of SuDs retrofit helps to address these health issues.

Economically, the security of the reputation of a business is very important. In recent years, the importance of reputation has become increasingly apparent with the rising effect of damages which are caused by flood events. A good reputation for an organisation will inform the consumer's preference and external support for an organisation in critical times and enhance the value of an organisation in the market place (Epstein, 2018). Economic growth can also be stimulated by SuDs retrofit, through attractiveness of an area to new businesses, creation of jobs from the installation and maintenance of SuDs, and the improved productivity of workers when the environment is positively impacted by aesthetics, improved health conditions, improved air quality and many others (West et al., 2009; Kruger, 2014). Carpenter (2012) found that an aesthetically improved environment with the installation of SuDs can improve tourist attractions and recreation centres, with the aim of attracting visitors from both locally and internationally. Green infrastructure has been credited in the UK with significant impact in job creation (Chegut et al., 2014). Also in the United States, shoppers tend to stay longer when visits are made for business purposes, owing to the presence of green structures (Yi, 2014).

In addition, in projecting the cost of installing SuDs retrofit and the future effect on a community, most importantly when considering a value oriented structure, a conducive whole life costing (WLC) is guaranteed for a clearer understanding of the required costs. Lamond (2016) explains whole life costing as a methodology that gives a systematic economic consideration of all costs associated with SuDs retrofit. In considering this methodology, a number of factors are measured - finance, business costs and income from land sale, user costs. In order to deliver the best value for money, these factors are essential when measuring the economic implications in terms of the cost effectiveness of SuDs retrofit in a community.

Despite the increased flooding events in the UK, the uptake of SuDs retrofit as a flood risk management measure is still largely being ignored (Ossa-Moreno et al., 2017). The lack of experience of, and trust in some of the approaches is a major setback for the implementation of SuDs retrofit (Backhaus et al., 2016). Convincing stakeholders about the implementation of a new scheme is difficult when consideration is given to failed flood risk management schemes (Kundzewicz et al., 2017). 
Flood management in England and Wales is currently seen differently to water supply and water quality management terms (Kangalawe, 2017). In Wales, Natural Resource Wales (NRW) provide an oversight role in relation to all flood and coastal risk management in Wales and are responsible for managing flooding from main rivers, reservoirs and the sea including the provision of technical advice and support. While in England, The Department for Environment, Food and Rural Affairs (Defra) is the policy lead for flood and coastal erosion risk management in England. These bodies have got their individual policies which differ in some ways and hinders the possibility of collaborating efforts and budgets across these regions through major solutions which are able to manage existing challenges in a cost effective way (Cousins 2017).

The responsibility for the cost of maintaining and implementing SuDs retrofit is also a major barrier (Ashley et al., 2010). Like all drainage systems, SuDs retrofit should be inspected and maintained. This will ensure efficient operation and prevention of future failures. However, the lack of understanding of the cost of maintenance and implementation of this relatively new scheme is exacerbating its uptake.

\subsection{COST BENEFIT ANALYSIS APPROACHES}

In approaching real life problems, a number of decision making tools have been developed such as Cost benefit analysis (CBA), cost-effectiveness analysis, cost-utility analysis, riskbenefit analysis, economic impact analysis, fiscal impact analysis, and social return on investment (SROI) analysis (Greco, et al, 2005; Snell 2011).

Cost effectiveness analysis (CEA) is an economic analysis tool, distinct from CBA which assigns value to the measure of effect. It compares relative costs and outcomes of different actions (Price, 2018). CEA is applied to planning and management of many types of organised activities and it is used in many aspects of life which includes the health sector where it may be inappropriate to monetize health effects. Campillo-Artero and Ortún (2016) defined CEA as a measure of health that developed countries use in making funding decisions, which is aimed at publicly funding health technologies that produce the greatest health gain at a given cost. CEA has faced some setbacks due to the fact that it reflects mistrust of the underlying methods or the motives of the parties conducting the analyses, or a desire on the part of many to deny or downplay the underlying problem of resource scarcity in health care due to the ethical difficulty in monetizing health effects. However, CEA is widely accepted as a useful tool for 
resource allocation. CEA is also not applicable in the context of this research,Brock (2004) opined that there are important ethical and value choices to be made in constructing and using CEA; these choices are not merely technical, empirical, or economic, but moral and value choices as well. These moral choices explains why it may be difficult to quantify outcomes of health issues and its suitability for a cost benefit analysis model.

Cost utility analysis (CUA) is similar to CEA, it is mostly used in pharma economics especially health technology assessments (HTA). It estimates the ratio between the cost of a healthrelated intervention and the benefit it produces in terms of the number of years lived in full health by the beneficiaries. CUA are estimates of health outcomes and costs of competing alternatives and is widely accepted as a useful tool for resource allocation. Health outcomes are commonly summarized as quality-adjusted life-years (QALY), which are a combination of quantity and quality of life (Kuntz, 2016). There are continuing controversies about the QALY unit, which is used to measure the outcome of the findings from CUA. One very important aspect of the CUA is the term 'quality'. Richardson (1994) identified the fact that there are varieties of meanings to the 'quality' aspect of CUA, with different scaling techniques and concepts which makes CUA inappropriate as an idea economic tool. A similar principle that governs the ethical and moral implication of using CEA in this research context is also applicable with CUA because of the difficulty associated with monetizing its outcomes.

Risk-benefit analysis (RBA) seeks to quantify the risk and benefits by employing the ratio of the risk of an action to its potential benefits (Guo, et al, 2010). RBA for a clinical trial is provisionally based on the preclinical phase of the medicinal product. The sponsorinvestigator team needs to evaluate the toxicological tests and results as well as submit the data to the competent health authorities, with a projection of all the possible risks for the proposed trial subjects (Fortwengel, 2011). This tool does not have the facility to determine the cost of a product which is required under the determination of the cost effectiveness of SuDs retrofit because it is not a financial based tool. This is therefore outside the scope of the research on the cost and benefit of the installation of the retrofit of SuDs.

Furthermore, the economic impact analysis (EIA) examines the effect of an event on the economy in a specific location, this ranges from a single neighbourhood to the entire globe. EIA measures changes in business revenue, profits, personal wages which can lead to the suggestion of policies and laws that could improve the economy. Drucker (2015) described EIA method as an analytical technique that is predicated on economic stability, yet commonly 
applied to situations that violate this condition with little consideration of the implications. EIA is basically a tool which is useful for the wider economy of a nation and in determining the political and economic stability.

Fiscal impact analysis (FIA) is a tool that is used to compare project or policy change, changes in governmental costs against changes in governmental revenue. Moore (2015) describes the FIA tool as a revenue-to-cost relationship which explains the implication of a proposed revenue to be generated from a new development in any location. This can either be positive or negative, depending on whether the revenue generated is greater or lower than the cost. For example, Town A is a major residential development project that requires new services and facilities such as fire and police protection, libraries, schools, parks, and others. At the same time, Town A will as a result of this project receive new revenues such as property tax revenues, local sales tax revenue, and other taxes and fees. FIA therefore compares the total expected costs to the total expected revenues to determine the net fiscal impact of the proposed development on Town A.

The CBA approach has been selected in this study in order to undertake an economic appraisal of the monetary and non-monetary benefits of the uptake of SuDS retrofit. The CBA approach suggests that any new initiative or investment decision should only be adopted if its expected benefits (political, social, environmental and moral) exceed its costs (Wildavsky, 2018).

Rotimi (2014) successfully applied the CBA concept to property level floor adaptation (PLFRA) measures, incorporating a recognition of the intangible benefits. This provided a robust mechanism for decision making on investments in property level floor adaptation (PLFRA) measures by homeowners. This model was designed to advise homeowners of the potential benefits of investing in property level floor adaptation (PLFRA) measures. Another example can be seen in the analysis carried out on the report on the cost benefit analysis of Western Cape climate change response (Parmesan, 2006). The Western Cape Government (WCG) recognised the risks posed by climate change to its economy, population, ecosystems and infrastructure and sought for measures to mitigate its effect by the use of the CBA model. The use of the CBA model helped lead to a better and more informed implementation process of activities that are economically valuable in terms of reducing climate change risks.

The CBA tool enables a clear monetary comparison of the costs and benefits of the installation of SuDS, thereby facilitating the decision making process and providing an appreciation of the cost effectiveness of the range of alternative solutions. A unique feature in this study is the 
application of the Choice Modelling Method (CMM). The CMM Method is to be employed to elicit willingness to pay (WTP) values from property owners to obtain the non-monetary benefits of the installation of SuDS retrofit. The advantage of using CMM is that respondents are presented with various alternative descriptions of non-monetary benefits, differentiated by their attributes and levels, and are asked to rank the various alternatives, to rate them or to choose their most preferred (Hanley, et al., 2001). By including price/cost as one of the attributes of the non-monetary benefits, willingness to pay can be indirectly recovered from people's rankings, ratings or choices.

\subsection{EVALUATION OF THE COSTS AND BENEFITS OF SUDS RETROFIT}

One of the important recommendations from the Pitt (2008) review was to encourage property owners to take up the responsibility of reducing the effect of flood events on their properties by the uptake of available flood risk measures. Although the uptake of SuDs remains challenging owing to the complexity in its monetary and non-monetary benefits, there is continuous growth in public interest (Ossa-Moreno, 2017). The proposed CBA conceptual framework has taken into consideration the key components associated with the cost and benefits of SuDs retrofit and could help support further uptake.

\subsection{The Costs of SuDs Retrofit}

In the development of the CBA conceptual framework, the method for estimating additional costs of the measures adopted is to proceed stage-by-stage from the beginning to the end of the estimation activity. This method, whilst time consuming, tends to be the best because it outlines a detailed and more informed process in handling the breakdown of the costs of installing SuDs.

Figure 1 is a representation of the stages that a typical SuDs retrofit installation is expected to go through for the full costs (and benefits) to be determined. These stages include the preliminary stage, implementation stage and the maintenance stage.

According to Merz et al. (2004), in estimating the cost of flood adaptation measures, the ability to categorise the flood mitigation measures by building design and construction process in the 
required order has the potential to lead to a better outcome. The decision to invest in SuDs as a retrofit is determined by the type of property and the level of impact flood events have had and will have on the property. Therefore, it is important to consider the impact of flood characteristics in this evaluation process.

According to Proverbs and Soetanto (2004), the damage caused by flood events on any property is a function of variables including flood characteristics such as the depth of flood water, velocity, history, duration, probability and the source of the flood. Among these characteristics, flood depth, duration, probability, history, velocity are essential because they play significant roles in the extent of damage experienced by any property. They also help to determine the additional costs before installation as a result of the extent of damage and the repair work required. 
Flood Characteristics

Flood duration, depth and probability

Costs from the installation of SuDS retrofit

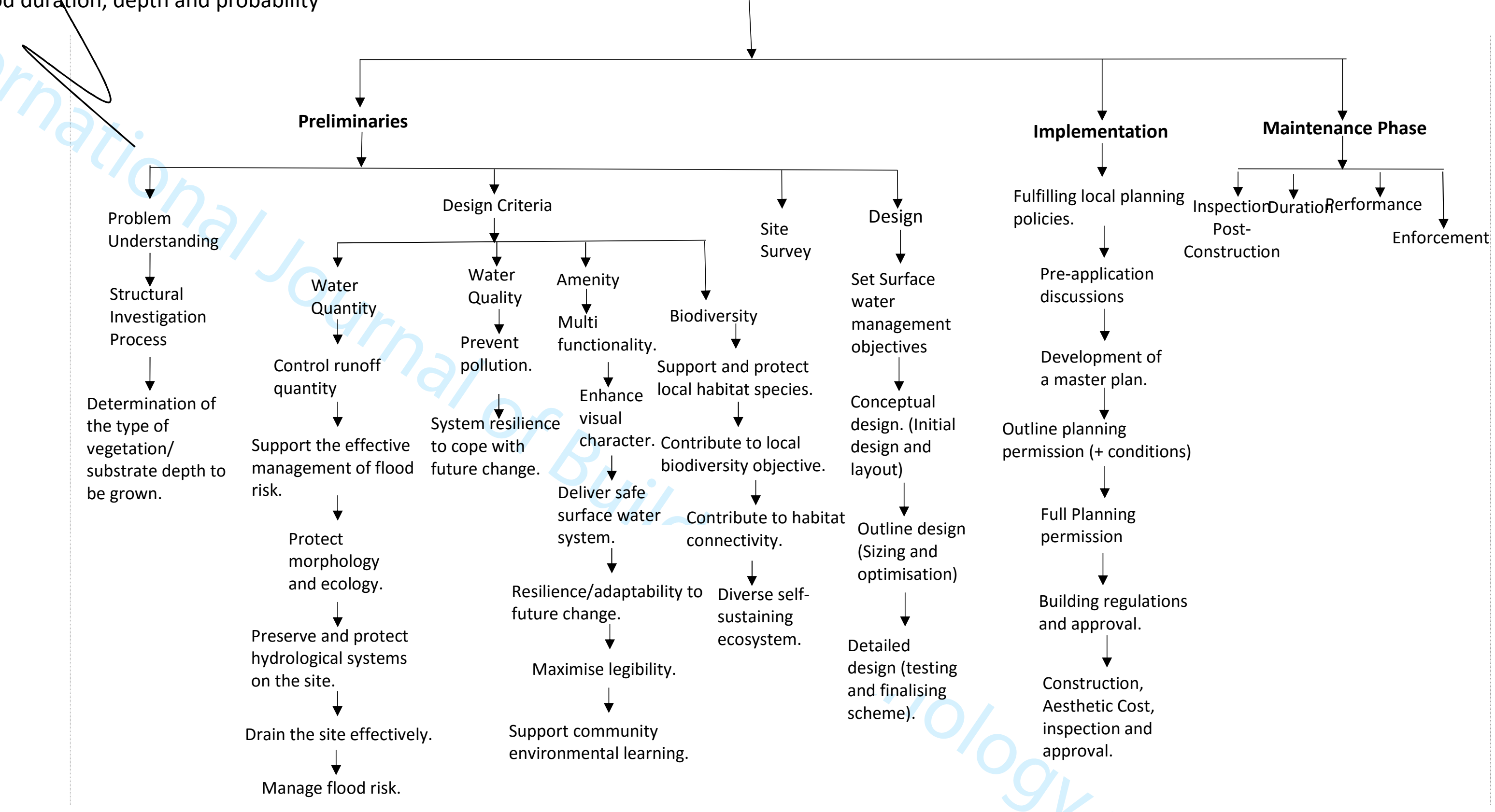

Figure 1: Cost for the installation of SuDS retrofit 


\subsection{THE BENEFITS OF SUDS RETROFIT}

The uptake of SuDS as a retrofit could be of benefit to different stakeholders including property owners and users, insurance companies, flood management professionals and the government. The benefits of SuDS retrofit can be grouped into tangible benefits (Monetary) and intangible benefits (non-monetary) as shown in Figure 2.

To evaluate these benefits, several considerations needs to be involved, such as taking into account the benefits accruing to and the cost incurred by the property owner (PenningRowsell et al., 2005); selecting appropriate prices for evaluating the benefits and costs in monetary terms and adjusting the future prices of benefits to present values to make them comparable with the costs (Joseph, 2014). This means that despite the fact that the benefits and costs are from different sources, it is important that a systematic procedure is established to allow the proper evaluation of every parameter.

Bozman et al. (2015) described tangible benefits as quantifiable especially monetarily, these are identified as reduced cost of infrastructure, improved aesthetic value, reduction of surface water charges, flood risk reduction and improved market value of the property. The intangible benefits are subdivided into the benefits accrued by the property owner and the benefits accrued by the wider community. For the accrued benefits by the property owner, this includes rainwater harvesting, reduced post-flood recovery inconvenience, security of business reputation, reduced interruption to business activities, reduced cost of business assets and values, reduced insurance claim, increased property protection, reduced/elimination of property content evacuation and reduction in energy usage.

In terms of the benefits accrued by the wider community, this includes economic improvements, air and water quality, reduced loss of life, reduction/elimination of diseases, reduction /elimination of infections, reduction/elimination of muddy part ways, reduced loss of ecological and cultural values, reduction/elimination of depression, reduction/elimination of anxiety, reduction /elimination of stress, reduction of G.P. visits, habitat for wildlife.

Figure 2 shows the stages in evaluating the value of benefits that will accrue with the uptake of SuDS. These are in two forms, the actual market data for tangible benefits and the WTP values on the intangible benefits. This is important because the application of the concept of $\mathrm{CBA}$ requires that both the costs and benefits have to be in the same unit of measurement before any decision can be made on whether a project is cost-effective or not (Joseph, 2014). 


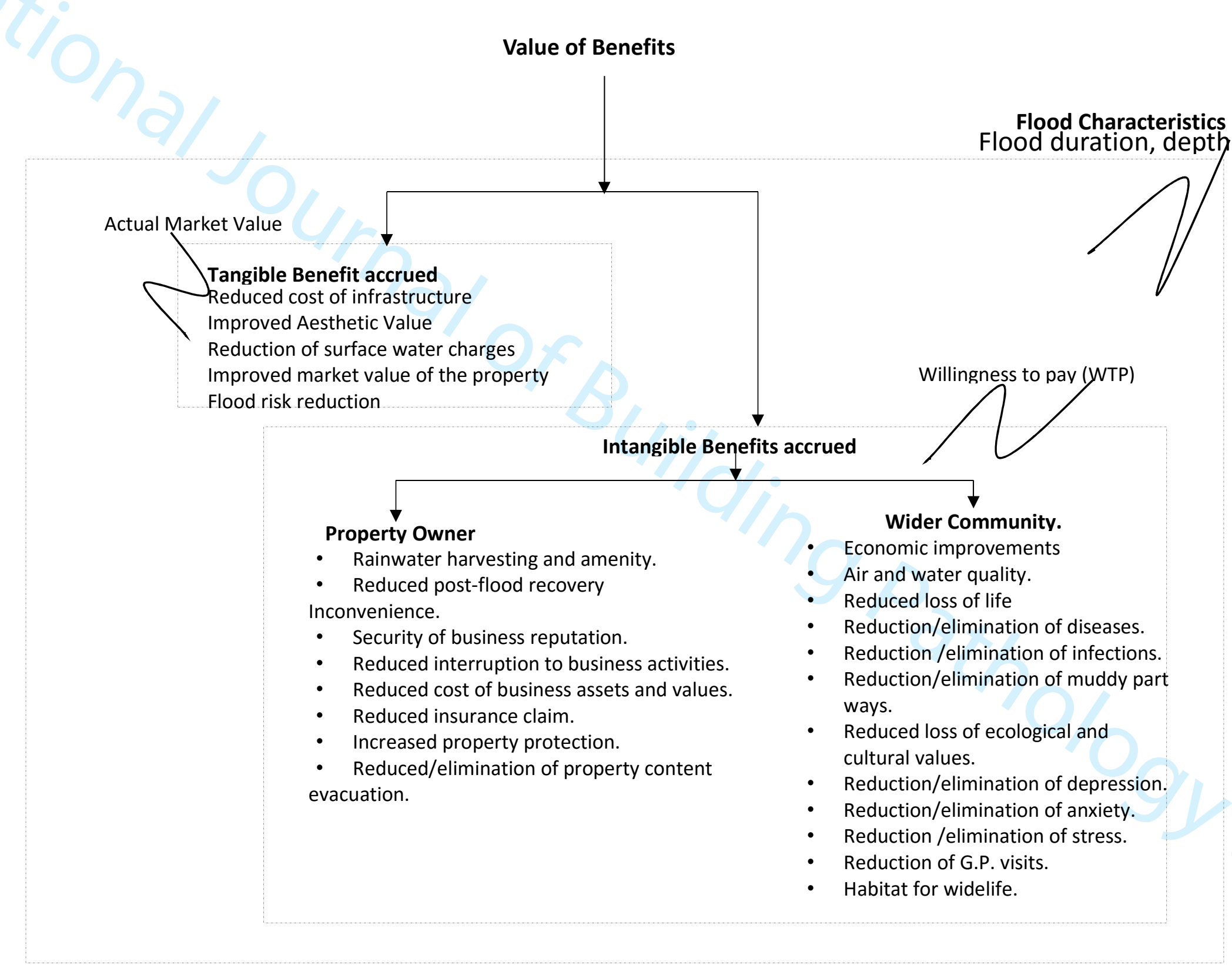

Figure 2: Value of Benefits 


\subsection{WILLINGNESS TO PAY (WTP)}

Intangible benefits by their subjective nature are difficult to quantify and are said to be more personal to the victim of a flood event (Joseph, 2014). This impact depends on the relationship of the individual to the loss or damage which had been experienced from the flood. Therefore, ignoring the intangible benefits of SuDS retrofit can lead to an incomplete understanding of the full benefits. Non-availability of locations where intangible benefits of flooding are being considered, makes its evaluation more difficult (Joseph, 2014; Markantonis and Meyer, 2011), this is why it is usually left out of the CBA appraisal for flood adaptation measures.

The intangible benefits of SuDS retrofit can be evaluated by using one of the stated preference methods (SPM) of valuation referred to as choice modelling method (CMM), this can be used to elicit WTP estimates from property owners.

\section{Choice modelling method (CMM)}

The CMM is a family of survey-based methodologies for modelling preference for different options of choices. CMM gives more detailed options to respondents enabling a more explicit understanding of their needs. With the choice modelling method, respondents are presented with various alternative descriptions of the intangible benefits with different levels of financial commitments which would then be ranked from most preferred till the less preferred. By including price as one of the rankings, willingness to pay can then be indirectly recovered from the ratings or choices (Snell, 2011).

In a typical CMM technique, individual preferences are uncovered in the survey by asking respondents to rank the options presented to them, to score them or to choose their most preferred. These different ways of measuring preferences correspond to different variants of the CMM approach. There are four major variants: choice experiments, contingent ranking, contingent rating and paired comparisons (Olazak, et al, 2018).

An example of the application of CMM in the context of this study is shown in Figure 3.

\begin{tabular}{|r|l|l|}
\hline $\begin{array}{l}\text { SuDs retrofit type (Green } \\
\text { Roof) }\end{array}$ & Intangible Benefit & WTP value $(\mathrm{f})$ \\
\hline 1. 20years maintenance & Economic Improvement & 20,000 \\
$2 . \quad 15 y e a r s ~ m a i n t e n a n c e$ & & 15,000 \\
\hline
\end{tabular}


Figure 3: Example of the application of the CMM to intangible benefits.

\subsection{Flood Probability}

One major factor in determining the cost effectiveness of SuDS retrofit is flood probability (flood return period). Destro et al. (2018) described it as the estimate of the likelihood of the occurrence of a flood event. It is a key determining factor in the installation of SuDS retrofit, as it affects the accrued benefits. A study by Thurston et al. (2008) determined that a flood resistance measure could be said to be worth an economical value for properties with a 50 year return period. However, properties that experience flooding events more than once in every ten years, the benefits outweigh the up-front investment. Also, Joseph et al. (2014) found that the adoption of resilience measures will be more economical for properties which are located in areas with up to 25 years return period. However, properties that experience flooding events more than once in every five years, the benefits are said to outweigh the upfront investment. Therefore, in considering the accrued benefits from repeat flooding in high risk areas, flood probability (flood return period) is an important variable which should be included in the CBA conceptual model.

\subsection{THE CONCEPTUAL FRAMEWORK}

Figure 4 represents the CBA framework for comparing the costs and benefits of SuDs retrofit in commercial properties. This CBA framework gives a detailed description of the monetary and non-monetary value of the installation of SuDs retrofit in a commercial property. Oladunjoye et al. (2017) identify this as a gap that as resulted in a reluctance towards the uptake of SuDs retrofit to mitigate flood risks, hence the need for a detailed framework that will give a robust understanding of the monetary values.

The framework is represented by a pivoted depiction representing the implications of the impact costs and the benefits accrued from a typical SuDs retrofit. Stovin (2013) and Lamond 
et al. (2014) opined that when considering the decision for the uptake of an element like SuDs retrofit, it is important that if the cost of installing SuDS retrofit is less than the benefit, then investment in it is advised but if it is otherwise, it is not advisable to go ahead with its uptake.

In a typical CBA model, it is important that costs and benefits are well defined. Snell (2011) described CBA as a formal technique adopted for clear, systematic and rational decision making especially when faced with complex alternatives or uncertain data. Hence a detailed CBA model will make it easy for clarity and a rational decision to be attained. Although CBA is a well-established tool, its application in this context is quite unique. In this framework, in a bid to derive a robust outcome, consideration was given to the involvement of indirect property users in terms of the benefits accrued from the installation of SuDs retrofit.

The framework is divided into two parts representing firstly, the details of the costs of installing a typical SuDs retrofit for a commercial property and secondly, representing details of the accrued benefits. The CBA conceptual framework is developed by introducing required elements of the costs versus the tangible and intangible benefits as it affects commercial properties and reflects the hypothesised relationship between costs and benefits of a typical SuDs retrofit installation. The costs and benefits of the SuDs retrofit are linked together to produce a CBA conceptual framework which incorporates all necessary parameters.

A clear and well detailed process of installing a typical SuDs retrofit has been employed, to form the framework. This framework represents a contribution to the study of SuDs retrofit in the context of commercial property. In terms of the benefits accrued, these are considered in the context of both direct and indirect users of a commercial property. This is important because consideration is needed to be given to both the property owner and other users of the property such as customers, employees and suppliers.

Included in the framework are the flood characteristics which have influence on the outcome of the costs of installation and also the benefits. Flood duration, depth, velocity, probability and history are vital determinants in the determination of the outcome of installing SuDs retrofit. Soetanto, et al, (2004) opined that the damage caused by any disaster is highly dependent on the scale and nature of that disaster. In this context, the damage cause to a commercial property is dependent on the flood characteristics. 


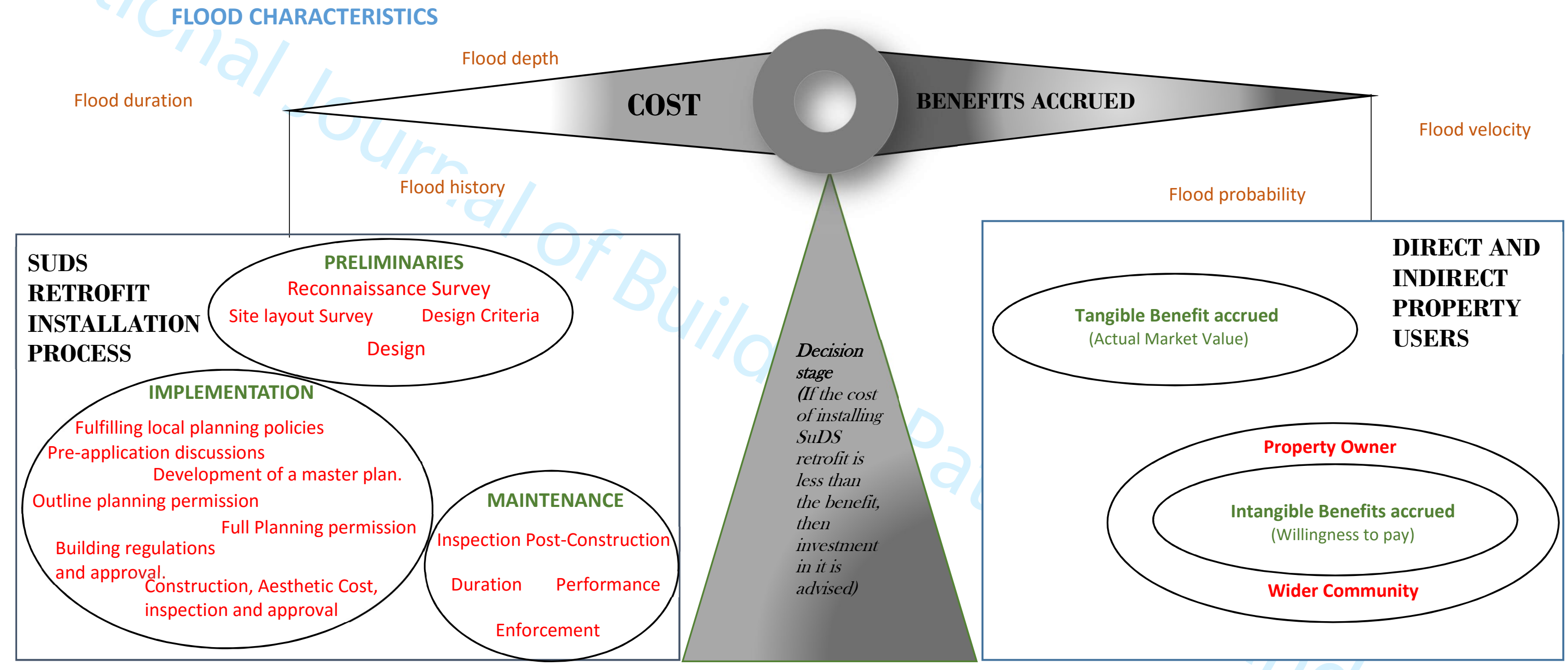

Figure 4: CBA Conceptual Framework for comparing the costs and benefits of suds retrofit in commercial properties 


\subsection{CONCLUSIONS}

The development of a CBA conceptual framework for the costs and benefits of SuDs retrofit has been discussed and presented. This framework highlights the essential elements of the costs and benefits of SuDs retrofit which need to be examined in the context of commercial properties. The CBA framework provides an in depth means of assessing the actual cost and benefits of the installation of SuDs retrofit. By combining the relevant elements in each section of the framework, the full costs and benefits of retrofitting SuDs can be established. This would help in the decision-making process when faced with choosing to invest in any type of SuDs retrofit.

The conceptual framework presented gives the much needed understanding about the cost effectiveness and benefits of the installation of the retrofit of SuDs which is previously lacking in the literature. The framework draws on the various approaches used in estimating costs and benefits of SuDs retrofit which will assist decision makers and end users in deciding how best to reduce the impacts of flooding.

A full understanding of the costs and benefits of retrofitting SuDs will help to inform better decision making in choosing the most appropriate and cost effective means of retrofitting SuDs for any given location. The proposed model is expected to be used by flood risk management professionals, property professionals and commercial property owners of the potential benefits of investing in the installation of SuDS. This study will help develop our understanding of the full costs and benefits accrued from the retrofit of SuDs and so lead to an increase in uptake. Also, details about the benefits accrued by indirect users of the commercial property will inform a robust understanding of the advantage that these set of users will derive from the uptake of SuDs retrofit. The model developed here is specifically for commercial properties but many of the principles applied would be equally relevant to other types of property.

However, one major challenge with this research is with quantifying the intangible accrued benefits from installing SuDs retrofit. Putting a value to these parameters are very important but difficult for most professionals to accomplish. Quillin (2010) described intangible benefits as hidden jewels that do exit and need to be accepted as valid. However, being able to validate this parameters stands as a major difficulty. 


\section{References}

Alexander, M., Priest, S.J., Micou, P., Tapsell, S.M., Green, C.H., Parker, D.J. and Homewood, S., (2016). Analysing and evaluating flood risk governance in England-enhancing societal resilience through comprehensive and aligned flood risk governance arrangements.

Agwuele, A. ed., (2013). Development, Modernism and Modernity in Africa. Routledge.

Armstrong, J.T., 2010. Extensive green roof design in the City of Cape Town: barriers and opportunities for developing a green industry (Doctoral dissertation, University of Cape Town).

Armstrong, M. and Taylor, S., 2014. Armstrong's handbook of human resource management practice. Kogan Page Publishers.

Ashley, R.M., Walker, A.L., D’Arcy, B., Wilson, S., Illman, S., Shaffer, P., Woods-Ballard, P. and Chatfield, C., 2015. UK sustainable drainage systems: past, present and future. In Proceedings of ICE-Civil Engineering (Vol. 168, No. 3, pp. 125-130). Thomas Telford.

Assaf, S.A. and Al-Hejji, S., (2006). Causes of delay in large construction projects. International journal of project management, 24(4), pp.349-357.

Baron, N. and Petersen, L.K., (2016). Understanding Controversies in Urban Climate Change Adaptation. A case study of the role of homeowners in the process of climate change adaptation in Copenhagen. Nordic Journal of Science and Technology, 3(2), pp. 4-13.

Bhattacharya, N., Lamond, J., Proverbs, D. and Hammond, F., 2013. Development of conceptual framework for understanding vulnerability of commercial property values towards flooding. International Journal of Disaster Resilience in the Built Environment, 4(3), pp. 334351.

Blevins, R.L., Lal, R., Doran, J.W., Langdale, G.W. and Frye, W.W., 2018. Conservation tillage for erosion control and soil quality. In Advances in soil and water conservation (pp. 51-68). Routledge.

Booth, C., and Charlesworth, S., (2017). Sustainable Surface Water Management: A hand book for SuDS. Wiley Blackwell, p3.Campillo-Artero, C., \& Ortún, V. (2016). Cost-effectiveness analysis: Why and how. Revista Española De Cardiología (English Edition), 69(4), 370-373. doi:10.1016/j.rec.2016.01.012 
Bozman, C. S., Friesner, D., McPherson, M. Q., \& Chase, N. M. (2015). Intangible and tangible value: brand equity benefits associated with collegiate athletics. International Journal of Sports Marketing and Sponsorship, 16(4), 22-45.

Brock, D. (2004). Ethical issues in the use of cost effectiveness analysis for the prioritization of health resources. In Handbook of bioethics (pp. 353-380). Springer, Dordrecht.

Carboni, D., Gluhak, A., McCann, J.A. and Beach, T.H., (2016). Contextualising Water Use in Residential Settings: A Survey of Non-Intrusive Techniques and Approaches. Sensors, 16(5), pp. 738.

Chofreh, A. G., Goni, F. A., \& Klemeš, J. J. (2018). Evaluation of a framework for sustainable Enterprise Resource Planning systems implementation. Journal of Cleaner Production, 190, 778-786.

Destro, E., Amponsah, W., Nikolopoulos, E.I., Marchi, L., Marra, F., Zoccatelli, D. and Borga, M., (2018). Coupled prediction of flash flood response and debris flow occurrence: application on an alpine extreme flood event. Journal of Hydrology.

Ellis, J.B., (2013). Sustainable surface water management and green infrastructure in UK urban catchment planning. Journal of Environmental Planning and Management, 56(1), pp.24-41.

Epstein, M.J., 2018. Making sustainability work: Best practices in managing and measuring corporate social, environmental and economic impacts. Routledge

Fisher-Jeffes, Lloyd \& Armitage, Neil. (2011). A simple economic model for the comparison of SUDS and conventional drainage systems in South Africa.

Forman, R.T., Sperling, D., Bissonette, J.A., Clevenger, A.P., Cutshall, C.D., Dale, V.H., Fahrig, L., France, R.L., Heanue, K., Goldman, C.R. and Jones, J., (2003). Road ecology: science and solutions. Island press.

Fortwengel, G. (2011). Risk-Benefit Analysis. In Guide for Investigator Initiated Trials (pp. 1-3). Karger Publishers.

Foster, J., Lowe, A. and Winkelman, S., 2011. The value of green infrastructure for urban climate adaptation. Center for Clean Air Policy, 750, pp.1-52. 
Green, C., 2010. Towards sustainable flood risk management. International Journal of Disaster Risk Science, 1(1), pp.33-43.

Greenough, G., McGeehin, M., Bernard, S.M., Trtanj, J., Riad, J. and Engelberg, D., (2001). The potential impacts of climate variability and change on health impacts of extreme weather events in the United States. Environmental health perspectives, 109(Suppl 2), p.191.

Guo, J. J., Pandey, S., Doyle, J., Bian, B., Lis, Y., \& Raisch, D. W. (2010). A review of quantitative risk-benefit methodologies for assessing drug safety and efficacy-report of the ISPOR riskbenefit management working group. Value in Health, 13(5), 657-666.

Hanley, N., Mourato, S., \& Wright, R. E. (2001). Choice modelling approaches: a superior alternative for environmental valuatioin?. Journal of economic surveys, 15(3), 435-462.

Joseph R., (2014). Development of a comprehensive systematic quantification of the costs and benefits (CB) of property level flood risk adaptation measures in England(Doctoral dissertation, University of the West of England).

Kirby, A., (2005), June. SuDS- innovation or a tried and tested practice?. In Proceedings of the Institution of Civil Engineers-Municipal Engineer (Vol. 158, No. 2, pp. 115-122). London: Published for the Institution of Civil Engineers by Thomas Telford Services, c1992-.

Kuntz, K. M., ScD. (2016). Decision modeling for cost-utility analysis. Value in Health, 19(6), 700-701. doi:10.1016/j.jval.2016.06.003

Lamond, J.E., (2016). Whole Life Costing and Multiple Benefits of Sustainable Drainage. Sustainable Surface Water Management: A Handbook for SUDS, p.235.

Landon, J.R., 2014. Booker tropical soil manual: a handbook for soil survey and agricultural land evaluation in the tropics and subtropics. Routledge.

Lazzarini, L., 2018. The role of planning in shaping better urban-rural relationships in Bristol City Region. Land Use Policy, 71, pp.311-319.

Lead, C., (2018). Urban Planning and Urban Design. Climate Change and Cities: Second Assessment Report of the Urban Climate Change Research Network, p.139. 
Locatelli, L., (2016). Modelling the impact of Water Sensitive Urban Design technologies on the urban water cycle.

Malulu, I.C., (2016). Opportunities for integrating Sustainable urban Drainage Systems (SuDS) in informal settlements as part of stormwater management (Doctoral dissertation, Stellenbosch: Stellenbosch University).

Markantonis, V. and Meyer, V., (2011). Valuating the intangible effects of natural hazards: a review and evaluation of the cost-assessment methods. In European Society for Ecological Economics conference.

Moore, P. (2015). Fiscal Impact Analysis. In Encyclopedia of Public Administration and Public Policy-5 Volume Set (pp. 1-5). Routledge.

O'BRIEN, C.D., 2015. Sustainable drainage system (SuDS) ponds in Inverness, UK and the favourable conservation status of amphibians. Urban Ecosystems, 18(1), pp. 321-331.

Oladunjoye, O., Proverbs, D., Collins, B., (2017). https://www.researchgate.net/publication/319718484_the_barriers_and_opportunities_to_ the_retrofit_of_sustainable_urban_drainage_systems_suds_towards_improving_flood_risk_ mitigation_in_urban_areas_in_the_uk [accessed Apr 10 2018].

Olszak, C., \& Mach-Król, M. (2018). A Conceptual Framework for Assessing an Organization's Readiness to Adopt Big Data. Sustainability, 10(10), 3734.

Ossa-Moreno, J., Smith, K.M. and Mijic, A., (2017). Economic analysis of wider benefits to facilitate SuDS uptake in London, UK. Sustainable Cities and Society, 28, pp.411-419.

Parmesan, C. (2006). Ecological and evolutionary responses to recent climate change. Annu. Rev. Ecol. Evol. Syst., 37, 637-669.

Price, R., 2018. Cost-effectiveness of disaster risk reduction and adaptation to climate change.

Proverbs, David \& Xiao, Hong \& Oladokun, Victor \& Adedeji, Taiwo. (2018). Towards a conceptual framework for property level flood resilience. International Journal of Safety and Security Engineering. 8. 10.2495/SAFE-V8-N4-493-504. 
Richardson, J. (1994). Cost utility analysis: what should be measured?. Social science and medicine, 39(1), 7-22.

Robichaud, L.B. and Anantatmula, V.S., 2010. Greening project management practices for sustainable construction. Journal of Management in Engineering, 27(1), pp.48-57.

Robinson, D.J., 2018. Assessing Green Infrastructure Needs in Hampton Roads, Virginia and Identifying the Role of Virginia Cooperative Extension (Doctoral dissertation, Virginia Tech).

Rushton, A., Croucher, P. and Baker, P., 2014. The handbook of logistics and distribution management: Understanding the supply chain. Kogan Page Publishers.

Shrivastava, A.K., Yadav, S., Yadav, L.S., Khan, S., Khan, A.R. and Sharma, S., 2018. Global Warming Issues-Need for Sustainable Drainage System in Urban Areas-Green Construction Technologies. In Energy and Environment (pp. 15-28). Springer, Singapore.

Sieker, H., Helm, B., Krebs, P., Schlottmann, P. and Tränker, J., 2008. Flexibility-a planning criterion for stormwater management. In 11th International Conference on Urban Drainage. Edingburgh.

Smith, R.E., 2010. Prefab architecture: A guide to modular design and construction. John Wiley \& Sons.

Smith, J.O.M.K.M. and Mijic, A., (2016). Economic analysis of wider benefits to facilitate SuDS. Environment, 33(1), pp.70-84.

Snell, M., (2011). Cost-benefit analysis: A practical guide. 2nd Edition. London: Thomas Telford.

Soetanto, R., \& Proverbs, D. G. (2004). Impact of flood characteristics on damage caused to UK domestic properties: the perceptions of building surveyors. Structural Survey, 22(2), 95104.

Stovin, V., Swan, A. and Moore, S., (2007). Retrofit SuDS for urban water quality enhancement. Dept. of Civil and Structural Engineering, Univ. of Sheffield, Sheffield, UK. 
Stovin, V., (2010). The potential of green roofs to manage urban stormwater. Water and Environment Journal, 24(3), pp.192-199.

Thurston, N., Finlinson, B, Breakspear, R., Williams, N., Shaw, J. and Chatterton, J. (2008), Developing the Evidence Base for Flood Resistance and Resilience Joint Defra/EA Flood and Coastal Erosion Risk Management R\&D, DEFRA, London.

Vargas Renzi, F., (2018). BIM Application in Construction Management (Master's thesis, Universitat Politècnica de Catalunya).

Vincent, S.U., Radhakrishnan, M., Hayde, L. and Pathirana, A., (2017). Enhancing the Economic Value of Large Investments in Sustainable Drainage Systems (SuDS) through Inclusion of Ecosystems Services Benefits. Water, 9(11), p.841.

Walsh, C., Burke, S., Glendinning, S. and Dawson, R., (2016). Alternative business models for flood risk management infrastructure. In E3S Web of Conferences (Vol. 7, p. 20015). EDP Sciences.

Weimer, D.L. and Vining, A.R., (2017). Policy analysis: Concepts and practice. Taylor \& Francis.

Wildavsky, A., (2018). Economy and environment rationality and ritual. In The art and craft of policy analysis (pp. 193-214). Palgrave Macmillan, Cham.

Wilkinson, S.J. and Dixon, T. eds., 2016. Green Roof Retrofit: building urban resilience. John Wiley \& Sons.

Winsemius, H.C., Jongman, B., Veldkamp, T.I., Hallegatte, S., Bangalore, M. and Ward, P.J., (2018). Disaster risk, climate change, and poverty: Assessing the global exposure of poor people to floods and droughts. Environment and Development Economics, pp.1-21.

Woods Ballard, B., Wilson, S., Udale-Clarke, H., Illman, S., Scott, T., Ashley, R. and Kellagher, R., (2015). The SuDS Manual, C753, CIRIA, London, UK. ISBN 978-0-86017-760-9. http://www. susdrain. org/resources/SuDS_Manual. html. 
A COST BENEFIT ANALYSIS MODEL FOR THE RETROFIT OF SUSTAINABLE URBAN DRAINAGE SYSTEMS TOWARDS IMPROVED FLOOD RISK MITIGATION

\begin{tabular}{|c|c|}
\hline Purpose of this paper & $\begin{array}{l}\text { The Environment Agency estimates that one } \\
\text { in six homes in England (approximately } \\
5.2 \text { million properties) are at risk from } \\
\text { flooding and } 185,000 \text { commercial properties } \\
\text { are located in flood prone areas. Further, an } \\
\text { estimated } 10,000 \text { new homes are built on } \\
\text { flood plains yearly. The UK has witnessed a } \\
\text { significant increase in flood events over the } \\
\text { past } 10 \text { years. During this period, there has } \\
\text { been growing research attention into } \\
\text { measures to mitigate the effects of flooding, } \\
\text { including the benefits of deploying } \\
\text { Sustainable Urban Drainage Systems (SuDs) } \\
\text { in new developments or as a retrofit. This } \\
\text { study presents the development of a cost- } \\
\text { benefit analysis model for the retrofit of } \\
\text { SuDs focusing on the potential for improved } \\
\text { flood risk mitigation in the context of } \\
\text { commercial properties. }\end{array}$ \\
\hline Design/methodology/approach & $\begin{array}{l}\text { A synthesis of the flood risk management } \\
\text { and SuDs literature is used to inform the } \\
\text { development of a conceptual cost-benefit } \\
\text { analysis model for the retrofit of SuDs and } \\
\text { focusing on the potential for improved flood } \\
\text { risk mitigation in the context of commercial } \\
\text { properties. }\end{array}$ \\
\hline Findings (mandatory) & $\begin{array}{l}\text { Sustainable urban drainage systems have } \\
\text { been applied successfully in different parts }\end{array}$ \\
\hline
\end{tabular}


of the world, however, the uptake of SuDs, in particular the retrofit of SuDs, has been restricted by a number of issues including a lack of experience and trust in their performance and a lack of understanding in their true benefits. In particular, there is limited experience of retrofitting SuDs and there are no well established procedures for evaluating the feasibility, value or costeffectiveness of doing this.

This offers the potential to support the UK government's flood risk management policy by helping to increase the resilience of properties, whilst offering other benefits to communities such as improvements in air quality and biodiversity and also presenting a clearer understanding of the monetary and non-monetary implication to owners of commercial properties for a more informed and acceptable uptake of SuDs retrofit.

The proposed model will allow a more comprehensive understanding of the costs and associated benefits associated with SuDs retrofit, highlighting the flood risk mitigation benefits that might accrue over a period of time for commercial property.

Keywords: Flood risk, Commercial properties, Conceptual framework, Costs, Benefits. 


\section{$1.0 \quad$ INTRODUCTION}

Globally, more than $80 \%$ of the population living on land are prone to flooding (Winsemius, et al., 2018). In 2007, the worst flooding experience in the UK since 1947 coincided with the start of the worst financial crisis since the 1930s. These had a major impact on people, properties and businesses and brought the need for a better risk management system. In the UK, the environment agency estimates that one in six homes in England (approximately 5.2million properties) are at risk from flooding. Included in this statistics is an average of 10,000 homes which are built on flood plains yearly, while 185,000 commercial properties are located in flood prone areas. These properties are valued at over $f 801$ billion which accounts for 15.8 per cent of the value of total buildings and 2.2 per cent of total assets in the UK (Bhattacharya, et al., 2013). One in six residential and commercial properties, which form about 2.4 million in England are at risk of flooding from main rivers or the sea.

The commercial property sector plays an important role in the UK economy, both as a direct or indirect employer, a generator of output, and in providing other sectors including retailers, financial and business services, with a critical factor of production, that is, the location from which their business is done. It is estimated that the total output in the sector in 2011 was around $f 41 \mathrm{bn}$ which is equivalent to $3.2 \%$ of UK gross value added (GVA) and total employment of over 800,000 . The sector makes a substantial contribution to the exchequer, with an estimated contribution in VAT and PAYE income tax of approximately f6.5bn. Any disruption to the activities in this sector would be detrimental to the growth of the UK economy in total.

Sustainable Urban Drainage Systems (SuDs) are a system which could be used to protect commercial properties from flooding. SuDs are uniquely designed to mimic natural infiltration patterns, so that they can reduce the risk of flooding by reducing runoff volume and attenuation peak flows. Kirby (2005) described SuDs as more sustainable than conventional drainage methods because they are designed to manage flow rates, protect or enhance water quality and are sympathetic to the environmental setting and the needs of the local community by dealing with runoff close to where rain falls or attenuating flows and controlling discharges downstream.

However, the uptake of SuDs and the retrofit of SuDs has been restricted by a number of issues including, a lack of experience and trust in such schemes, and a lack of understanding of their 
wider benefits (Oladunjoye, et al., 2017; Malulu, 2016; Ossa-Moreno, 2017; Ellis, 2013; Lamond, 2016). There has been limited research on the retrofit of SuDs and there are no well established procedures for evaluating the feasibility, value or cost-effectiveness of doing this (Ossa-Moreno, 2017 and Alexander, et al., 2016). Lead (2018) revealed that 68\% of construction professionals felt there was a lack of understanding of SuDs among key decisionmakers. However, there remains growing interest in the introduction of this technology (Stovin, 2010) and stakeholders and researchers have sought to develop modalities on how to make SuDs more acceptable and relevant in the UK (Carboni, 2016). This study aims to help facilitate a deeper appreciation of the monetary and non-monetary value of SuDs retrofit with the development of a cost benefit analysis (CBA) model towards improving uptake and thereby improving flood risk mitigation in commercial properties in the UK. The results of this study will help to develop a better understanding of the longterm viability of SuDs retrofit and its monetary value, in order to encourage uptake by key decision makers involved in the development and redevelopment of buildings.

\subsection{SUSTAINABLE URBAN DRAINAGE SYSTEMS}

Sustainable urban drainage systems (SuDs) is a generic term that refers to various measures used to control the effect of surface water runoff in the environment (Locatelli, 2016). Booth and Charlesworth (2017) defined sustainable drainage as the management of rainwater which includes snow and other precipitation, with the aim of reducing damages caused by flooding events, improving the quality of water, the improvement and protection of the environment, the improvement and safety of the health of the residents and the process of ensuring the effective stability and durability of drainage systems. Baron and Petersen (2016) further described SuDs as an important contribution to urban climate change adaptation.

SuDs replicate the natural drainage processes of an area through the use of vegetation-based interventions such as swales, water gardens, and green roofs, which increase localised infiltration, attenuation and/or detention of stormwater. Hence, SuDs improves flood alleviation capacity in any community. SuDs are essential for the reduction in the quantity of surface water that flows off a surface and are useful for different purposes including reduction in runoff by, for example, the installation of green roofs or other SuDs which could result in savings in wastewater disposal (Wilkinson, and Dixon, 2016). The most well used SuDs are rainwater harvesting systems, green roofs, swales, rainwater beds and permeable surfaces as 
well as open drainage waterways and reservoirs for excess rainwater (Baron and Petersen, 2016). All these solutions aim to absorb, evaporate and/or channel rainwater so it does not end up in the sewage system.

\subsection{Retrofit of Sustainable Urban Drainage Systems}

SuDs retrofit is a storm water management process which is aimed at addressing urban water quality and the problems associated with flooding (Walsh, et al, 2016). Retrofit is used when SuDs are proposed for the replacement or augmentation of an existing drainage system (Smith, 2016). Examples of retrofitting SuDs can be seen in the installation of green roofs, the diversion of roof drainage from a combined sewer system into a garden soakaway, and the conveyance of road runoff via roadside swales into a pond sited in an area of open space (Ellis, 2013). These represent alternative ways of influencing the quality of the water downstream and the problems relating to it, thereby providing a more effective, resilient and sustainable approach. For SuDs to be acceptable, three core attributes are essential: economic viability, resilience and sustainability (Lead, 2018).

In considering the economic viability of SuDs retrofit, it is important that SuDs retrofit is affordable in costs and benefit for it to be accepted as a potential replacement for the existing drainage system. Fisher-Jeffes et al. (2011) identified that impacts such has aesthetics, economic value, rainwater harvesting, influences the choices made by individuals and organisations as it affects the cost and sale of properties. Ossa-Moreno et al. (2017) opined that for a SuDs retrofit installation to be economically feasible or viable, the wider benefits would need to be taken into account.

Resilience is multifaceted and is defined in different ways by various professionals. Proverbs et al., (2018) defines resilience as the ability of a system to return to its stable state after a momentary disturbance. Therefore, the acceptance of SuDs retrofit in terms of its resilience requires that the installation of SuDs retrofit would help to restore any flood affected area into a more attractive place.

According to Sieker et al. (2008), SuDs are known to be more adaptable and flexible than traditional solutions, allowing future modification to cope with climate and other changes in urban areas. Therefore, if SuDs retrofit can be incorporated into existing developed areas, the opportunities for delivering sustainable solutions that offer multiple benefits will be much greater. 


\subsection{The Implementation of the Retrofit of SuDs}

In this section, various benefits and barriers to the uptake of SuDs retrofit have been identified. The implication of the impact of these factors are further discussed.

\section{Processes of the implementation of the retrofit of SuDs}

A number of benefits that cut across various positive improvements in schemes and the lives of people have been identified. For example, Malulu (2016) found that a common SuDs intervention scheme entails the carrying out of works to rivers with the aim of increasing their capacity to carry flood flows. Friberg et al. (2016) identify a further scheme involving channel maintenance or enlarging the channel cross section and thereby increasing the flow of surface water by extending the capacity. The mitigation of the heat island effect and noise, the improvement in air and water quality and the provision of sites for recreation or urban amenities are various ways by which the ecosystem is sustained through SUDS retrofit (Demuzere et al., 2014; Ellis, 2013; Kazmierczak et al., 2010).

Other benefits of SuDs retrofit is in the reduced cost of infrastructure by the introduction of green infrastructure. Ellis (2013) argues that conventional drainage systems cannot provide the expected solution to any flood mitigation process but an extended approach based on the introduction of retrofit SuDs, in the likes of micro-and meso-vegetative SuDS systems into a wider green infrastructure(GI) framework, can effectively address on-site and catchment urban surface water issues. Foster et al. (2011), identified the importance of the aesthetic value of a building or location which is increased by the installation of SuDs retrofit by way of green infrastructure, creating habitat for wildlife, by constructing swales and other forms.

Health improvements from the use of SuDs is also an important benefit to every citizen. Lamond et al. (2015) affirm the importance of an improved flood risk management system to manage the growing pressure of the effect of flooding events on the health of the occupants of any community. Greenough et al. (2001) address the health effects of flooding which are typically associated with disasters. These are direct morbidity and mortality and secondary or indirect health impacts. A direct impact includes an impaired public health infrastructure, reduced access to health care facilities, and psychological and social effects. While indirect effects could result in the alteration of ecologic systems which may result in land covers (i.e, grass, asphalt, trees etc) being damaged, and the abundance and distribution of disease- 
carrying insects, rodents and some other vectors. An improved health system through the application of SuDs retrofit helps to address these health issues.

Economically, the security of the reputation of a business is very important. In recent years, the importance of reputation has become increasingly apparent with the rising effect of damages which are caused by flood events. A good reputation for an organisation will inform the consumer's preference and external support for an organisation in critical times and enhance the value of an organisation in the market place (Epstein, 2018). Economic growth can also be stimulated by SuDs retrofit, through attractiveness of an area to new businesses, creation of jobs from the installation and maintenance of SuDs, and the improved productivity of workers when the environment is positively impacted by aesthetics, improved health conditions, improved air quality and many others (West et al., 2009; Kruger, 2014). Carpenter (2012) found that an aesthetically improved environment with the installation of SuDs can improve tourist attractions and recreation centres, with the aim of attracting visitors from both locally and internationally. Green infrastructure has been credited in the UK with significant impact in job creation (Chegut et al., 2014). Also in the United States, shoppers tend to stay longer when visits are made for business purposes, owing to the presence of green structures (Yi, 2014).

In addition, in projecting the cost of installing SuDs retrofit and the future effect on a community, most importantly when considering a value oriented structure, a conducive whole life costing $(W L C)$ is guaranteed for a clearer understanding of the required costs. Lamond (2016) explains whole life costing as a methodology that gives a systematic economic consideration of all costs associated with SuDs retrofit. In considering this methodology, a number of factors are measured - finance, business costs and income from land sale, user costs. In order to deliver the best value for money, these factors are essential when measuring the economic implications in terms of the cost effectiveness of SuDs retrofit in a community. Despite the increased flooding events in the UK, the uptake of SuDs retrofit as a flood risk management measure is still largely being ignored (Ossa-Moreno et al., 2017). The lack of experience of, and trust in some of the approaches is a major setback for the implementation of SuDs retrofit (Backhaus et al., 2016). Convincing stakeholders about the implementation of a new scheme is difficult when consideration is given to failed flood risk management schemes (Kundzewicz et al., 2017). 
Flood management in England and Wales is currently seen differently to water supply and water quality management terms (Kangalawe, 2017). In Wales, Natural Resource Wales (NRW) provide an oversight role in relation to all flood and coastal risk management in Wales and are responsible for managing flooding from main rivers, reservoirs and the sea including the provision of technical advice and support. While in England, The Department for Environment, Food and Rural Affairs (Defra) is the policy lead for flood and coastal erosion risk management in England. These bodies have got their individual policies which differ in some ways and hinders the possibility of collaborating efforts and budgets across these regions through major solutions which are able to manage existing challenges in a cost effective way (Cousins 2017).

The responsibility for the cost of maintaining and implementing SuDs retrofit is also a major barrier (Ashley et al., 2010). Like all drainage systems, SuDs retrofit should be inspected and maintained. This will ensure efficient operation and prevention of future failures. However, the lack of understanding of the cost of maintenance and implementation of this relatively new scheme is exacerbating its uptake.

\subsection{COST BENEFIT ANALYSIS APPROACHES}

In approaching real life problems, a number of decision making tools have been developed such as Cost benefit analysis (CBA), cost-effectiveness analysis, cost-utility analysis, riskbenefit analysis, economic impact analysis, fiscal impact analysis, and social return on investment (SROI) analysis (Greco, et al, 2005; Snell 2011).

Cost effectiveness analysis (CEA) is an economic analysis tool, distinct from CBA which assigns value to the measure of effect. It compares relative costs and outcomes of different actions (Price, 2018). CEA is applied to planning and management of many types of organised activities and it is used in many aspects of life which includes the health sector where it may be inappropriate to monetize health effects. Campillo-Artero and Ortún (2016) defined CEA as a measure of health that developed countries use in making funding decisions, which is aimed at publicly funding health technologies that produce the greatest health gain at a given cost. CEA has faced some setbacks due to the fact that it reflects mistrust of the underlying methods or the motives of the parties conducting the analyses, or a desire on the part of many to deny or downplay the underlying problem of resource scarcity in health care due to the ethical difficulty in monetizing health effects. However, CEA is widely accepted as a useful tool for 
resource allocation. CEA is also not applicable in the context of this research,Brock (2004) opined that there are important ethical and value choices to be made in constructing and using CEA; these choices are not merely technical, empirical, or economic, but moral and value choices as well. These moral choices explains why it may be difficult to quantify outcomes of health issues and its suitability for a cost benefit analysis model.

Cost utility analysis (CUA) is similar to CEA, it is mostly used in pharma economics especially health technology assessments (HTA). It estimates the ratio between the cost of a healthrelated intervention and the benefit it produces in terms of the number of years lived in full health by the beneficiaries. CUA are estimates of health outcomes and costs of competing alternatives and is widely accepted as a useful tool for resource allocation. Health outcomes are commonly summarized as quality-adjusted life-years (QALY), which are a combination of quantity and quality of life (Kuntz, 2016). There are continuing controversies about the QALY unit, which is used to measure the outcome of the findings from CUA. One very important aspect of the CUA is the term 'quality'. Richardson (1994) identified the fact that there are varieties of meanings to the 'quality' aspect of CUA, with different scaling techniques and concepts which makes CUA inappropriate as an idea economic tool. A similar principle that governs the ethical and moral implication of using CEA in this research context is also applicable with CUA because of the difficulty associated with monetizing its outcomes.

Risk-benefit analysis (RBA) seeks to quantify the risk and benefits by employing the ratio of the risk of an action to its potential benefits (Guo, et al, 2010). RBA for a clinical trial is provisionally based on the preclinical phase of the medicinal product. The sponsorinvestigator team needs to evaluate the toxicological tests and results as well as submit the data to the competent health authorities, with a projection of all the possible risks for the proposed trial subjects (Fortwengel, 2011). This tool does not have the facility to determine the cost of a product which is required under the determination of the cost effectiveness of SuDs retrofit because it is not a financial based tool. This is therefore outside the scope of the research on the cost and benefit of the installation of the retrofit of SuDs.

Furthermore, the economic impact analysis (EIA) examines the effect of an event on the economy in a specific location, this ranges from a single neighbourhood to the entire globe. EIA measures changes in business revenue, profits, personal wages which can lead to the suggestion of policies and laws that could improve the economy. Drucker (2015) described EIA method as an analytical technique that is predicated on economic stability, yet commonly 
applied to situations that violate this condition with little consideration of the implications. EIA is basically a tool which is useful for the wider economy of a nation and in determining the political and economic stability.

Fiscal impact analysis (FIA) is a tool that is used to compare project or policy change, changes in governmental costs against changes in governmental revenue. Moore (2015) describes the FIA tool as a revenue-to-cost relationship which explains the implication of a proposed revenue to be generated from a new development in any location. This can either be positive or negative, depending on whether the revenue generated is greater or lower than the cost. For example, Town A is a major residential development project that requires new services and facilities such as fire and police protection, libraries, schools, parks, and others. At the same time, Town A will as a result of this project receive new revenues such as property tax revenues, local sales tax revenue, and other taxes and fees. FIA therefore compares the total expected costs to the total expected revenues to determine the net fiscal impact of the proposed development on Town A.

The CBA approach has been selected in this study in order to undertake an economic appraisal of the monetary and non-monetary benefits of the uptake of SuDS retrofit. The CBA approach suggests that any new initiative or investment decision should only be adopted if its expected benefits (political, social, environmental and moral) exceed its costs (Wildavsky, 2018).

Rotimi (2014) successfully applied the CBA concept to property level floor adaptation (PLFRA) measures, incorporating a recognition of the intangible benefits. This provided a robust mechanism for decision making on investments in property level floor adaptation (PLFRA) measures by homeowners. This model was designed to advise homeowners of the potential benefits of investing in property level floor adaptation (PLFRA) measures. Another example can be seen in the analysis carried out on the report on the cost benefit analysis of Western Cape climate change response (Parmesan, 2006). The Western Cape Government (WCG) recognised the risks posed by climate change to its economy, population, ecosystems and infrastructure and sought for measures to mitigate its effect by the use of the CBA model. The use of the CBA model helped lead to a better and more informed implementation process of activities that are economically valuable in terms of reducing climate change risks.

The CBA tool enables a clear monetary comparison of the costs and benefits of the installation of SUDS, thereby facilitating the decision making process and providing an appreciation of the cost effectiveness of the range of alternative solutions. A unique feature in this study is the 
application of the Choice Modelling Method (CMM). The CMM Method is to be employed to elicit willingness to pay (WTP) values from property owners to obtain the non-monetary benefits of the installation of SuDS retrofit. The advantage of using CMM is that respondents are presented with various alternative descriptions of non-monetary benefits, differentiated by their attributes and levels, and are asked to rank the various alternatives, to rate them or to choose their most preferred (Hanley, et al., 2001). By including price/cost as one of the attributes of the non-monetary benefits, willingness to pay can be indirectly recovered from people's rankings, ratings or choices.

\subsection{EVALUATION OF THE COSTS AND BENEFITS OF SUDS RETROFIT}

One of the important recommendations from the Pitt (2008) review was to encourage property owners to take up the responsibility of reducing the effect of flood events on their properties by the uptake of available flood risk measures. Although the uptake of SuDs remains challenging owing to the complexity in its monetary and non-monetary benefits, there is continuous growth in public interest (Ossa-Moreno, 2017). The proposed CBA conceptual framework has taken into consideration the key components associated with the cost and benefits of SuDs retrofit and could help support further uptake.

\subsection{The Costs of SuDs Retrofit}

In the development of the CBA conceptual framework, the method for estimating additional costs of the measures adopted is to proceed stage-by-stage from the beginning to the end of the estimation activity. This method, whilst time consuming, tends to be the best because it outlines a detailed and more informed process in handling the breakdown of the costs of installing SuDs.

Figure 1 is a representation of the stages that a typical SuDs retrofit installation is expected to go through for the full costs (and benefits) to be determined. These stages include the preliminary stage, implementation stage and the maintenance stage.

According to Merz et al. (2004), in estimating the cost of flood adaptation measures, the ability to categorise the flood mitigation measures by building design and construction process in the 
required order has the potential to lead to a better outcome. The decision to invest in SuDs as a retrofit is determined by the type of property and the level of impact flood events have had and will have on the property. Therefore, it is important to consider the impact of flood characteristics in this evaluation process.

According to Proverbs and Soetanto (2004), the damage caused by flood events on any property is a function of variables including flood characteristics such as the depth of flood water, velocity, history, duration, probability and the source of the flood. Among these characteristics, flood depth, duration, probability, history, velocity are essential because they play significant roles in the extent of damage experienced by any property. They also help to determine the additional costs before installation as a result of the extent of damage and the repair work required. 
Flood Characteristics

depth and probability

Costs from the installation of SuDS retrofit

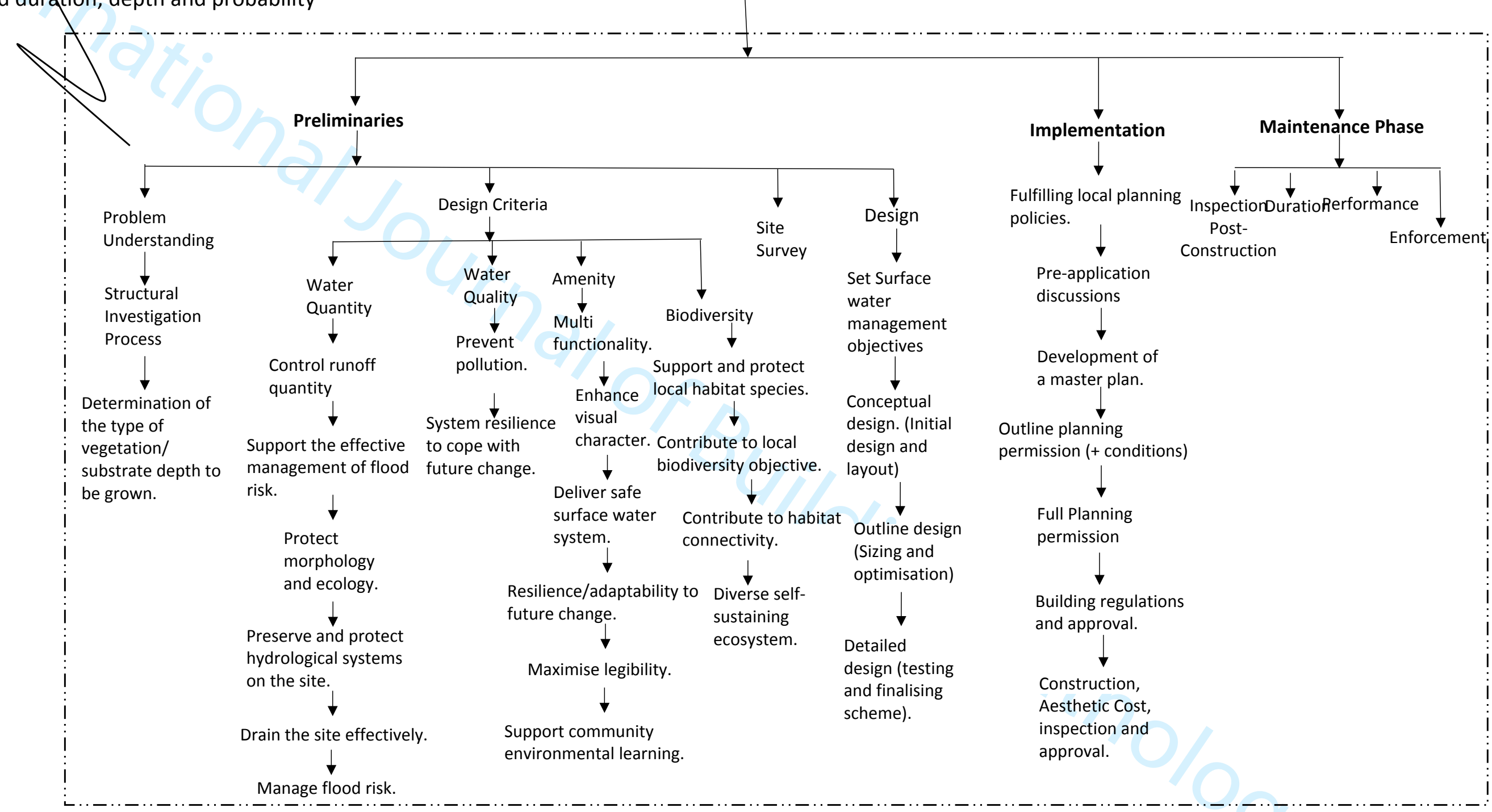

Figure 1: Cost for the installation of SuDS retrofit 


\subsection{THE BENEFITS OF SUDS RETROFIT}

The uptake of SuDS as a retrofit could be of benefit to different stakeholders including property owners and users, insurance companies, flood management professionals and the government. The benefits of SuDS retrofit can be grouped into tangible benefits (Monetary) and intangible benefits (non-monetary) as shown in Figure 2.

To evaluate these benefits, several considerations needs to be involved, such as taking into account the benefits accruing to and the cost incurred by the property owner (PenningRowsell et al., 2005); selecting appropriate prices for evaluating the benefits and costs in monetary terms and adjusting the future prices of benefits to present values to make them comparable with the costs (Joseph, 2014). This means that despite the fact that the benefits and costs are from different sources, it is important that a systematic procedure is established to allow the proper evaluation of every parameter.

Bozman et al. (2015) described tangible benefits as quantifiable especially monetarily, these are identified as reduced cost of infrastructure, improved aesthetic value, reduction of surface water charges, flood risk reduction and improved market value of the property. The intangible benefits are subdivided into the benefits accrued by the property owner and the benefits accrued by the wider community. For the accrued benefits by the property owner, this includes rainwater harvesting, reduced post-flood recovery inconvenience, security of business reputation, reduced interruption to business activities, reduced cost of business assets and values, reduced insurance claim, increased property protection, reduced/elimination of property content evacuation and reduction in energy usage.

In terms of the benefits accrued by the wider community, this includes economic improvements, air and water quality, reduced loss of life, reduction/elimination of diseases, reduction /elimination of infections, reduction/elimination of muddy part ways, reduced loss of ecological and cultural values, reduction/elimination of depression, reduction/elimination of anxiety, reduction /elimination of stress, reduction of G.P. visits, habitat for wildlife.

Figure 2 shows the stages in evaluating the value of benefits that will accrue with the uptake of SuDS. These are in two forms, the actual market data for tangible benefits and the WTP values on the intangible benefits. This is important because the application of the concept of $\mathrm{CBA}$ requires that both the costs and benefits have to be in the same unit of measurement before any decision can be made on whether a project is cost-effective or not (Joseph, 2014). 


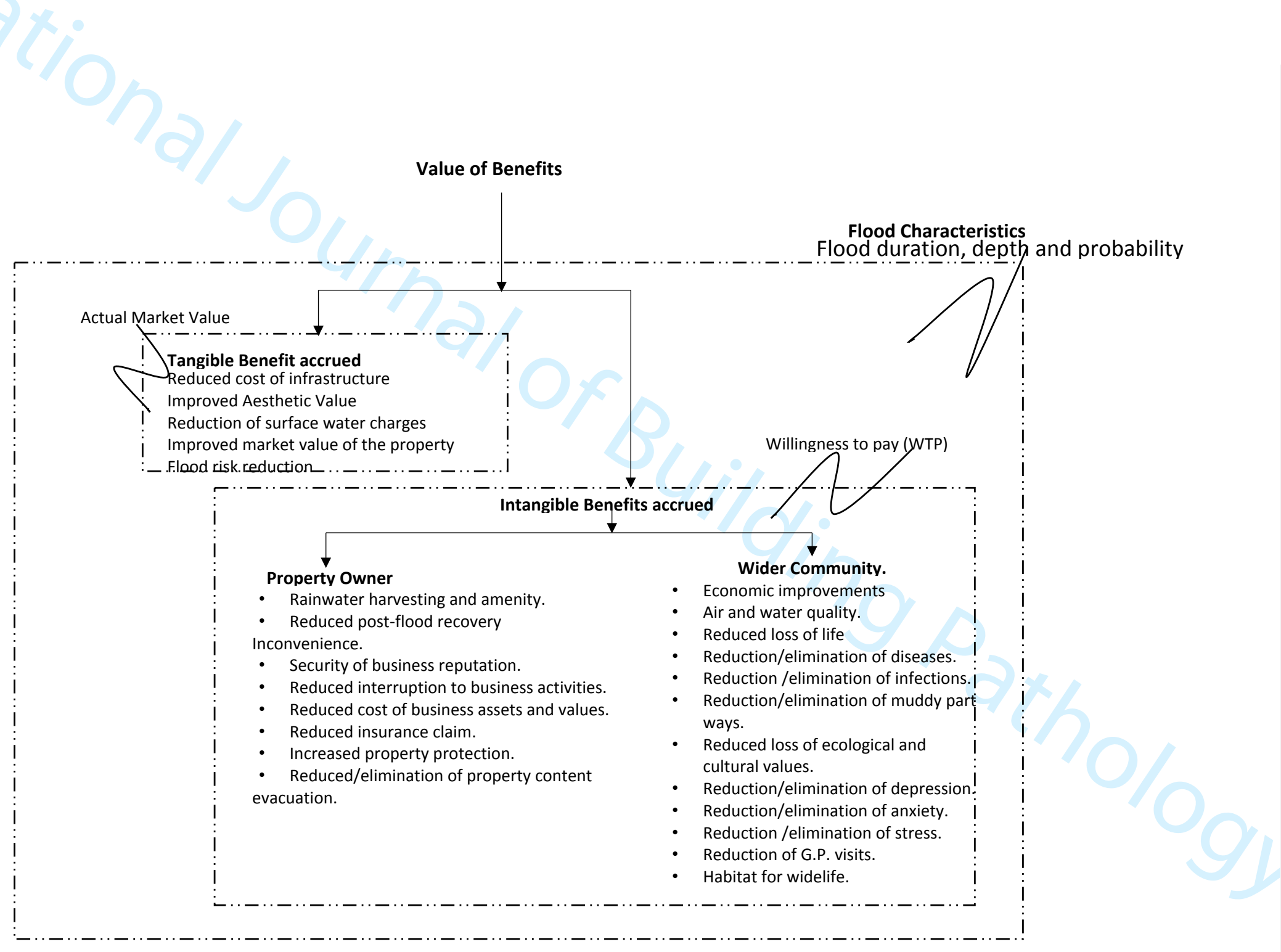

Figure 2: Value of Benefits 


\subsection{WILLINGNESS TO PAY (WTP)}

Intangible benefits by their subjective nature are difficult to quantify and are said to be more personal to the victim of a flood event (Joseph, 2014). This impact depends on the relationship of the individual to the loss or damage which had been experienced from the flood. Therefore, ignoring the intangible benefits of SuDS retrofit can lead to an incomplete understanding of the full benefits. Non-availability of locations where intangible benefits of flooding are being considered, makes its evaluation more difficult (Joseph, 2014; Markantonis and Meyer, 2011), this is why it is usually left out of the CBA appraisal for flood adaptation measures.

The intangible benefits of SuDS retrofit can be evaluated by using one of the stated preference methods (SPM) of valuation referred to as choice modelling method (CMM), this can be used to elicit WTP estimates from property owners.

\section{Choice modelling method (CMM)}

The CMM is a family of survey-based methodologies for modelling preference for different options of choices. CMM gives more detailed options to respondents enabling a more explicit understanding of their needs. With the choice modelling method, respondents are presented with various alternative descriptions of the intangible benefits with different levels of financial commitments which would then be ranked from most preferred till the less preferred. By including price as one of the rankings, willingness to pay can then be indirectly recovered from the ratings or choices (Snell, 2011).

In a typical CMM technique, individual preferences are uncovered in the survey by asking respondents to rank the options presented to them, to score them or to choose their most preferred. These different ways of measuring preferences correspond to different variants of the CMM approach. There are four major variants: choice experiments, contingent ranking, contingent rating and paired comparisons (Olazak, et al, 2018).

An example of the application of CMM in the context of this study is shown in Figure 3.

\begin{tabular}{|r|l|l|}
\hline $\begin{array}{l}\text { SuDs retrofit type (Green } \\
\text { Roof) }\end{array}$ & Intangible Benefit & WTP value (f) \\
\hline 1. 20years maintenance & Economic Improvement & 20,000 \\
2. 15years maintenance & & 15,000 \\
\hline
\end{tabular}


Figure 3: Example of the application of the CMM to intangible benefits.

\section{Discounting}

In considering the value of the benefits accrued from the installation of SuDS retrofit, it is important to apply a discount rate to both cost and benefits. Szekeres (2011) argues that it is useful to address how the discounting paradigm fares in the long run, especially as it affects climate change and environmental policy, to see if it suffers from any special limitations that need to be taken into account. Ackerman and Heinzerling (2001) described discounting as a tool used in CBA to compare the present costs and benefits and the implication for the future. This is the reduction in the value of future costs or benefits at a pre-specified rate, which depends on its temporal distance from a common time.

Given the value of money, a pound is worth more today than it would be worth tomorrow. Therefore, discounting is the primary factor used in pricing a stream of tomorrow's cash flow. Very often, decisions have to be made about whether to incur costs in the present, in return for benefits in the future, as in the case of investing in SuDS retrofit. Every investment requires this type of decision at one point or the other.

Since individuals and organisations have their preference as it relates to receiving benefits or incurring costs, time preferences also have to be accounted for through the process called discounting. The advantage of discounting is that it enforces consistency and it makes the assumptions explicit (Charness, et al, 2013).

In presenting the costs and benefits of SuDS retrofit in monetary terms, CBA follows standard economic practice in discounting future benefits and converting them to their equivalent value today, or present value. In the Economist view, when the time span is long and different generations are required to be involved in the costs and benefits of a particular project, the analogy to an individual investment decision breaks down (Keynes, 2018). Ackerman (2001) therefore suggested that when setting a discount rate for a project, it must be set to a very low level, so that an enhanced benefit is generated. 


\subsection{Flood Probability}

One major factor in determining the cost effectiveness of SuDS retrofit is flood probability (flood return period). Destro et al. (2018) described it as the estimate of the likelihood of the occurrence of a flood event. It is a key determining factor in the installation of SuDS retrofit, as it affects the accrued benefits. A study by Thurston et al. (2008) determined that a flood resistance measure could be said to be worth an economical value for properties with a 50 year return period. However, properties that experience flooding events more than once in every ten years, the benefits outweigh the up-front investment. Also, Joseph et al. (2014) found that the adoption of resilience measures will be more economical for properties which are located in areas with up to 25 years return period. However, properties that experience flooding events more than once in every five years, the benefits are said to outweigh the upfront investment. Therefore, in considering the accrued benefits from repeat flooding in high risk areas, flood probability (flood return period) is an important variable which should be included in the CBA conceptual model.

\subsection{THE CONCEPTUAL FRAMEWORK}

Figure 4 represents the CBA framework for comparing the costs and benefits of SuDs retrofit in commercial properties. This CBA framework gives a detailed description of the monetary and non-monetary value of the installation of SuDs retrofit in a commercial property. Oladunjoye et al. (2017) identify this as a gap that as resulted in a reluctance towards the uptake of SuDs retrofit to mitigate flood risks, hence the need for a detailed framework that will give a robust understanding of the monetary values.

The framework is represented by a pivoted depiction representing the implications of the impact costs and the benefits accrued from a typical SuDs retrofit. Stovin (2013) and Lamond et al. (2014) opined that when considering the decision for the uptake of an element like SuDs retrofit, it is important that if the cost of installing SuDS retrofit is less than the benefit, then investment in it is advised but if it is otherwise, it is not advisable to go ahead with its uptake. In a typical CBA model, it is important that costs and benefits are well defined. Snell (2011) described CBA as a formal technique adopted for clear, systematic and rational decision making especially when faced with complex alternatives or uncertain data. Hence a detailed CBA model will make it easy for clarity and a rational decision to be attained. Although CBA is 
a well-established tool, its application in this context is quite unique. In this framework, in a bid to derive a robust outcome, consideration was given to the involvement of indirect property users in terms of the benefits accrued from the installation of SuDs retrofit.

The framework is divided into two parts representing firstly, the details of the costs of installing a typical SuDs retrofit for a commercial property and secondly, representing details of the accrued benefits. The CBA conceptual framework is developed by introducing required elements of the costs versus the tangible and intangible benefits as it affects commercial properties and reflects the hypothesised relationship between costs and benefits of a typical SuDs retrofit installation. The costs and benefits of the SuDs retrofit are linked together to produce a CBA conceptual framework which incorporates all necessary parameters.

A clear and well detailed process of installing a typical SuDs retrofit has been employed, to form the framework. This framework represents a contribution to the study of SuDs retrofit in the context of commercial property. In terms of the benefits accrued, these are considered in the context of both direct and indirect users of a commercial property. This is important because consideration is needed to be given to both the property owner and other users of the property such as customers, employees and suppliers.

Included in the framework are the flood characteristics which have influence on the outcome of the costs of installation and also the benefits. Flood duration, depth, velocity, probability and history are vital determinants in the determination of the outcome of installing SuDs retrofit. Soetanto, et al, (2004) opined that the damage caused by any disaster is highly dependent on the scale and nature of that disaster. In this context, the damage cause to a commercial property is dependent on the flood characteristics. 


\subsection{CONCLUSIONS}

The development of a CBA conceptual framework for the costs and benefits of SuDs retrofit has been discussed and presented. This framework highlights the essential elements of the costs and benefits of SuDs retrofit which need to be examined in the context of commercial properties. The CBA framework provides an in depth means of assessing the actual cost and benefits of the installation of SuDs retrofit. By combining the relevant elements in each section of the framework, the full costs and benefits of retrofitting SuDs can be established. This would help in the decision-making process when faced with choosing to invest in any type of SuDs retrofit.

The conceptual framework presented gives the much needed understanding about the cost effectiveness and benefits of the installation of the retrofit of SuDs which is previously lacking in the literature. The framework draws on the various approaches used in estimating costs and benefits of SuDs retrofit which will assist decision makers and end users in deciding how best to reduce the impacts of flooding.

A full understanding of the costs and benefits of retrofitting SuDs will help to inform better decision making in choosing the most appropriate and cost effective means of retrofitting SuDs for any given location. The proposed model is expected to be used by flood risk management professionals, property professionals and commercial property owners of the potential benefits of investing in the installation of SuDS. This study will help develop our understanding of the full costs and benefits accrued from the retrofit of SuDs and so lead to an increase in uptake. Also, details about the benefits accrued by indirect users of the commercial property will inform a robust understanding of the advantage that these set of users will derive from the uptake of SuDs retrofit. The model developed here is specifically for commercial properties but many of the principles applied would be equally relevant to other types of property.

However, one major challenge with this research is with quantifying the intangible accrued benefits from installing SuDs retrofit. Putting a value to these parameters are very important but difficult for most professionals to accomplish. Quillin (2010) described intangible benefits as hidden jewels that do exit and need to be accepted as valid. However, being able to validate this parameters stands as a major difficulty. 


\section{References}

Ackerman, F., \& Heinzerling, L. (2001). Pricing the priceless: Cost-benefit analysis of environmental protection. U. Pa. L. Rev., 150, 1553.

Alexander, M., Priest, S.J., Micou, P., Tapsell, S.M., Green, C.H., Parker, D.J. and Homewood, S., (2016). Analysing and evaluating flood risk governance in England-enhancing societal resilience through comprehensive and aligned flood risk governance arrangements.

Agwuele, A. ed., (2013). Development, Modernism and Modernity in Africa. Routledge.

Armstrong, J.T., 2010. Extensive green roof design in the City of Cape Town: barriers and opportunities for developing a green industry (Doctoral dissertation, University of Cape Town).

Armstrong, M. and Taylor, S., 2014. Armstrong's handbook of human resource management practice. Kogan Page Publishers.

Ashley, R.M., Walker, A.L., D’Arcy, B., Wilson, S., Illman, S., Shaffer, P., Woods-Ballard, P. and Chatfield, C., 2015. UK sustainable drainage systems: past, present and future. In Proceedings of ICE-Civil Engineering (Vol. 168, No. 3, pp. 125-130). Thomas Telford.

Assaf, S.A. and Al-Hejji, S., (2006). Causes of delay in large construction projects. International journal of project management, 24(4), pp.349-357.

Backhaus, K., Erichson, B., Plinke, W., \& Weiber, R. (2016). Multivariate analysemethoden. Springer Berlin Heidelberg.

Baron, N. and Petersen, L.K., (2016). Understanding Controversies in Urban Climate Change Adaptation. A case study of the role of homeowners in the process of climate change adaptation in Copenhagen. Nordic Journal of Science and Technology, 3(2), pp. 4-13.

Bhattacharya, N., Lamond, J., Proverbs, D. and Hammond, F., 2013. Development of conceptual framework for understanding vulnerability of commercial property values towards flooding. International Journal of Disaster Resilience in the Built Environment, 4(3), pp. 334351. 


\begin{abstract}
Blevins, R.L., Lal, R., Doran, J.W., Langdale, G.W. and Frye, W.W., 2018. Conservation tillage
\end{abstract} for erosion control and soil quality. In Advances in soil and water conservation (pp. 51-68). Routledge.

Booth, C., and Charlesworth, S., (2017). Sustainable Surface Water Management: A hand book for SuDS. Wiley Blackwell, p3.Campillo-Artero, C., \& Ortún, V. (2016). Cost-effectiveness analysis: Why and how. Revista Española De Cardiología (English Edition), 69(4), 370-373. doi:10.1016/j.rec.2016.01.012

Bozman, C. S., Friesner, D., McPherson, M. Q., \& Chase, N. M. (2015). Intangible and tangible value: brand equity benefits associated with collegiate athletics. International Journal of Sports Marketing and Sponsorship, 16(4), 22-45.

Brock, D. (2004). Ethical issues in the use of cost effectiveness analysis for the prioritization of health resources. In Handbook of bioethics (pp. 353-380). Springer, Dordrecht.

Carboni, D., Gluhak, A., McCann, J.A. and Beach, T.H., (2016). Contextualising Water Use in Residential Settings: A Survey of Non-Intrusive Techniques and Approaches. Sensors, 16(5), pp. 738.

Charness, G., Gneezy, U., \& Imas, A. (2013). Experimental methods: Eliciting risk preferences. Journal of Economic Behavior \& Organization, 87, 43-51.

Chegut, A., Eichholtz, P., \& Kok, N. (2014). Supply, demand and the value of green buildings. Urban Studies, 51(1), 22-43.

Chofreh, A. G., Goni, F. A., \& Klemeš, J. J. (2018). Evaluation of a framework for sustainable Enterprise Resource Planning systems implementation. Journal of Cleaner Production, 190, 778-786.

Cousins, R. D. (2017). The Jeffreys-Lindley paradox and discovery criteria in high energy physics. Synthese, 194(2), 395-432.

Destro, E., Amponsah, W., Nikolopoulos, E.I., Marchi, L., Marra, F., Zoccatelli, D. and Borga, M., (2018). Coupled prediction of flash flood response and debris flow occurrence: application on an alpine extreme flood event. Journal of Hydrology. 
Ellis, J.B., (2013). Sustainable surface water management and green infrastructure in UK urban catchment planning. Journal of Environmental Planning and Management, 56(1), pp.24-41.

Epstein, M.J., 2018. Making sustainability work: Best practices in managing and measuring corporate social, environmental and economic impacts. Routledge

Fisher-Jeffes, Lloyd \& Armitage, Neil. (2011). A simple economic model for the comparison of SUDS and conventional drainage systems in South Africa.

Forman, R.T., Sperling, D., Bissonette, J.A., Clevenger, A.P., Cutshall, C.D., Dale, V.H., Fahrig, L., France, R.L., Heanue, K., Goldman, C.R. and Jones, J., (2003). Road ecology: science and solutions. Island press.

Fortwengel, G. (2011). Risk-Benefit Analysis. In Guide for Investigator Initiated Trials (pp. 1-3). Karger Publishers.

Foster, J., Lowe, A. and Winkelman, S., 2011. The value of green infrastructure for urban climate adaptation. Center for Clean Air Policy, 750, pp.1-52.

Green, C., 2010. Towards sustainable flood risk management. International Journal of Disaster Risk Science, 1(1), pp.33-43.

Greenough, G., McGeehin, M., Bernard, S.M., Trtanj, J., Riad, J. and Engelberg, D., (2001). The potential impacts of climate variability and change on health impacts of extreme weather events in the United States. Environmental health perspectives, 109(Suppl 2), p.191.

Guo, J. J., Pandey, S., Doyle, J., Bian, B., Lis, Y., \& Raisch, D. W. (2010). A review of quantitative risk-benefit methodologies for assessing drug safety and efficacy-report of the ISPOR riskbenefit management working group. Value in Health, 13(5), 657-666.

Hanley, N., Mourato, S., \& Wright, R. E. (2001). Choice modelling approaches: a superior alternative for environmental valuatioin?. Journal of economic surveys, 15(3), 435-462.

Joseph R., (2014). Development of a comprehensive systematic quantification of the costs and benefits ( $C B$ ) of property level flood risk adaptation measures in England (Doctoral dissertation, University of the West of England). 
Kangalawe, R. Y. (2017). Climate change impacts on water resource management and community livelihoods in the southern highlands of Tanzania. Climate and Development, 9(3), 191-201.

Kazmierczak, A., \& Carter, J. (2010). Adaptation to climate change using green and blue infrastructure. A database of case studies.

Keynes, J. M. (2018). The general theory of employment, interest, and money. Springer.

Kirby, A., (2005), June. SuDS- innovation or a tried and tested practice?. In Proceedings of the Institution of Civil Engineers-Municipal Engineer (Vol. 158, No. 2, pp. 115-122). London: Published for the Institution of Civil Engineers by Thomas Telford Services, c1992-.

Kruger, W. J. (2014). The integration of spatial-and infrastructure planning at municipal level (Doctoral dissertation).

Kundzewicz, Z. W., Krysanova, V., Dankers, R., Hirabayashi, Y., Kanae, S., Hattermann, F. F., ... \& Matczak, P. (2017). Differences in flood hazard projections in Europe-their causes and consequences for decision making. Hydrological Sciences Journal, 62(1), 1-14.

Kuntz, K. M., ScD. (2016). Decision modeling for cost-utility analysis. Value in Health, 19(6), 700-701. doi:10.1016/j.jval.2016.06.003

Lamond, J.E., (2016). Whole Life Costing and Multiple Benefits of Sustainable Drainage. Sustainable Surface Water Management: A Handbook for SUDS, p.235.

Landon, J.R., 2014. Booker tropical soil manual: a handbook for soil survey and agricultural land evaluation in the tropics and subtropics. Routledge.

Lazzarini, L., 2018. The role of planning in shaping better urban-rural relationships in Bristol City Region. Land Use Policy, 71, pp.311-319.

Lead, C., (2018). Urban Planning and Urban Design. Climate Change and Cities: Second Assessment Report of the Urban Climate Change Research Network, p.139.

Locatelli, L., (2016). Modelling the impact of Water Sensitive Urban Design technologies on the urban water cycle. 
Malulu, I.C., (2016). Opportunities for integrating Sustainable urban Drainage Systems (SuDS) in informal settlements as part of stormwater management (Doctoral dissertation, Stellenbosch: Stellenbosch University).

Markantonis, V. and Meyer, V., (2011). Valuating the intangible effects of natural hazards: a review and evaluation of the cost-assessment methods. In European Society for Ecological Economics conference.

Merz, B., Kreibich, H., Thieken, A., \& Schmidtke, R. (2004). Estimation uncertainty of direct monetary flood damage to buildings. Natural Hazards and Earth System Science, 4(1), $153-$ 163.

Moore, P. (2015). Fiscal Impact Analysis. In Encyclopedia of Public Administration and Public Policy-5 Volume Set (pp. 1-5). Routledge.

O'BRIEN, C.D., 2015. Sustainable drainage system (SuDS) ponds in Inverness, UK and the favourable conservation status of amphibians. Urban Ecosystems, 18(1), pp. 321-331.

Oladunjoye, O., Proverbs, D., Collins, B., (2017). https://www.researchgate.net/publication/319718484_the_barriers_and_opportunities_to_ the_retrofit_of_sustainable_urban_drainage_systems_suds_towards_improving_flood_risk_ mitigation_in_urban_areas_in_the_uk [accessed Apr 10 2018].

Olazak, C., \& Mach-Król, M. (2018). A Conceptual Framework for Assessing an Organization's Readiness to Adopt Big Data. Sustainability, 10(10), 3734.

Ossa-Moreno, J., Smith, K.M. and Mijic, A., (2017). Economic analysis of wider benefits to facilitate SuDS uptake in London, UK. Sustainable Cities and Society, 28, pp.411-419.

Parmesan, C. (2006). Ecological and evolutionary responses to recent climate change. Annu. Rev. Ecol. Evol. Syst., 37, 637-669.

Penning-Rowsell, E., Johnson, C., Tunstall, S., Tapsell, S., Morris, J., Chatterton, J., \& Green, C. (2005). The benefits of flood and coastal risk management: a handbook of assessment techniques. ISBN 1904750516.

Price, R., 2018. Cost-effectiveness of disaster risk reduction and adaptation to climate change. 
Proverbs, David \& Xiao, Hong \& Oladokun, Victor \& Adedeji, Taiwo. (2018). Towards a conceptual framework for property level flood resilience. International Journal of Safety and Security Engineering. 8. 10.2495/SAFE-V8-N4-493-504.

Richardson, J. (1994). Cost utility analysis: what should be measured?. Social science and medicine, 39(1), 7-22.

Robichaud, L.B. and Anantatmula, V.S., 2010. Greening project management practices for sustainable construction. Journal of Management in Engineering, 27(1), pp.48-57.

Robinson, D.J., 2018. Assessing Green Infrastructure Needs in Hampton Roads, Virginia and Identifying the Role of Virginia Cooperative Extension (Doctoral dissertation, Virginia Tech).

Rushton, A., Croucher, P. and Baker, P., 2014. The handbook of logistics and distribution management: Understanding the supply chain. Kogan Page Publishers.

Shrivastava, A.K., Yadav, S., Yadav, L.S., Khan, S., Khan, A.R. and Sharma, S., 2018. Global Warming Issues-Need for Sustainable Drainage System in Urban Areas-Green Construction Technologies. In Energy and Environment (pp. 15-28). Springer, Singapore.

Sieker, H., Helm, B., Krebs, P., Schlottmann, P. and Tränker, J., 2008. Flexibility-a planning criterion for stormwater management. In 11th International Conference on Urban Drainage. Edingburgh.

Smith, R.E., 2010. Prefab architecture: A guide to modular design and construction. John Wiley \& Sons.

Smith, J.O.M.K.M. and Mijic, A., (2016). Economic analysis of wider benefits to facilitate SuDS. Environment, 33(1), pp.70-84.

Snell, M., (2011). Cost-benefit analysis: A practical guide. 2nd Edition. London: Thomas Telford.

Soetanto, R., \& Proverbs, D. G. (2004). Impact of flood characteristics on damage caused to UK domestic properties: the perceptions of building surveyors. Structural Survey, 22(2), 95104. 
Stovin, V., Swan, A. and Moore, S., (2007). Retrofit SuDS for urban water quality enhancement. Dept. of Civil and Structural Engineering, Univ. of Sheffield, Sheffield, UK.

Stovin, V., (2010). The potential of green roofs to manage urban stormwater. Water and Environment Journal, 24(3), pp.192-199SZEKERES, S. (2011). discounting in cost-benefit analysis. Society and Economy, 33(2), 361-385. doi:10.1556/SocEc.33.2011.2.7

Thurston, N., Finlinson, B, Breakspear, R., Williams, N., Shaw, J. and Chatterton, J. (2008), Developing the Evidence Base for Flood Resistance and Resilience Joint Defra/EA Flood and Coastal Erosion Risk Management R\&D, DEFRA, London.

Vargas Renzi, F., (2018). BIM Application in Construction Management (Master's thesis, Universitat Politècnica de Catalunya).

Vincent, S.U., Radhakrishnan, M., Hayde, L. and Pathirana, A., (2017). Enhancing the Economic Value of Large Investments in Sustainable Drainage Systems (SuDS) through Inclusion of Ecosystems Services Benefits. Water, 9(11), p.841.

Walsh, C., Burke, S., Glendinning, S. and Dawson, R., (2016). Alternative business models for flood risk management infrastructure. In E3S Web of Conferences (Vol. 7, p. 20015). EDP Sciences.

Weimer, D.L. and Vining, A.R., (2017). Policy analysis: Concepts and practice. Taylor \& Francis. Wildavsky, A., (2018). Economy and environment rationality and ritual. In The art and craft of policy analysis (pp. 193-214). Palgrave Macmillan, Cham.

Wilkinson, S.J. and Dixon, T. eds., 2016. Green Roof Retrofit: building urban resilience. John Wiley \& Sons.

Winsemius, H.C., Jongman, B., Veldkamp, T.I., Hallegatte, S., Bangalore, M. and Ward, P.J., (2018). Disaster risk, climate change, and poverty: Assessing the global exposure of poor people to floods and droughts. Environment and Development Economics, pp.1-21. 
Woods Ballard, B., Wilson, S., Udale-Clarke, H., Illman, S., Scott, T., Ashley, R. and Kellagher, R., (2015). The SuDS Manual, C753, CIRIA, London, UK. ISBN 978-0-86017-760-9. http://www. susdrain. org/resources/SuDS_Manual. html.

Yi, S., Wang, X., Qin, Y., Xiang, B., \& Ding, Y. (2014). Responses of alpine grassland on QinghaiTibetan plateau to climate warming and permafrost degradation: a modeling perspective. Environmental Research Letters, 9(7), 074014. 


\section{A COST BENEFIT ANALYSIS MODEL FOR THE RETROFIT OF SUSTAINABLE URBAN DRAINAGE SYSTEMS TOWARDS IMPROVED FLOOD RISK MITIGATION}

\begin{tabular}{|c|c|}
\hline Purpose of this paper & $\begin{array}{l}\text { The Environment Agency estimates that one } \\
\text { in six homes in England (approximately } \\
5.2 \text { million properties) are at risk from } \\
\text { flooding and } 185,000 \text { commercial properties } \\
\text { are located in flood prone areas. Further, an } \\
\text { estimated } 10,000 \text { new homes are built on } \\
\text { flood plains yearly. The UK has witnessed a } \\
\text { significant increase in flood events over the } \\
\text { past } 10 \text { years. During this period, there has } \\
\text { been growing research attention into } \\
\text { measures to mitigate the effects of flooding, } \\
\text { including the benefits of deploying } \\
\text { Sustainable Urban Drainage Systems (SuDs) } \\
\text { in new developments or as a retrofit. This } \\
\text { study presents the development of a cost- } \\
\text { benefit analysis model for the retrofit of } \\
\text { SuDs focusing on the potential for improved } \\
\text { flood risk mitigation in the context of } \\
\text { commercial properties. }\end{array}$ \\
\hline Design/methodology/approach & $\begin{array}{l}\text { A synthesis of the flood risk management } \\
\text { and SuDs literature is used to inform the } \\
\text { development of a conceptual cost-benefit } \\
\text { analysis model for the retrofit of SuDs and } \\
\text { focusing on the potential for improved flood } \\
\text { risk mitigation in the context of commercial } \\
\text { properties. }\end{array}$ \\
\hline Findings (mandatory) & $\begin{array}{l}\text { Sustainable urban drainage systems have } \\
\text { been applied successfully in different parts }\end{array}$ \\
\hline
\end{tabular}




\begin{tabular}{|c|c|}
\hline & $\begin{array}{l}\text { of the world, however, the uptake of SuDs, } \\
\text { in particular the retrofit of SuDs, has been } \\
\text { restricted by a number of issues including a } \\
\text { lack of experience and trust in their } \\
\text { performance and a lack of understanding in } \\
\text { their true benefits. In particular, there is } \\
\text { limited experience of retrofitting SuDs and } \\
\text { there are no well established procedures for } \\
\text { evaluating the feasibility, value or cost- } \\
\text { effectiveness of doing this. }\end{array}$ \\
\hline Social implications & $\begin{array}{l}\text { This offers the potential to support the UK } \\
\text { government's flood risk management policy } \\
\text { by helping to increase the resilience of } \\
\text { properties, whilst offering other benefits to } \\
\text { communities such as improvements in air } \\
\text { quality and biodiversity and also presenting } \\
\text { a clearer understanding of the monetary and } \\
\text { non-monetary implication to owners of } \\
\text { commercial properties for a more informed } \\
\text { and acceptable uptake of SuDs retrofit. }\end{array}$ \\
\hline Originality/value (mandatory & $\begin{array}{l}\text { The proposed model will allow a more } \\
\text { comprehensive understanding of the costs } \\
\text { and associated benefits associated with } \\
\text { SuDs retrofit, highlighting the flood risk } \\
\text { mitigation benefits that might accrue over a } \\
\text { period of time for commercial property. }\end{array}$ \\
\hline
\end{tabular}

Keywords: Flood risk, Commercial properties, Conceptual framework, Costs, Benefits. 


\subsection{INTRODUCTION}

Globally, more than $80 \%$ of the population living on land are prone to flooding (Winsemius, et al., 2018). In 2007, the worst flooding experience in the UK since 1947 coincided with the start of the worst financial crisis since the 1930s. These had a major impact on people, properties and businesses and brought the need for a better risk management system. In the UK, the environment agency estimates that one in six homes in England (approximately 5.2million properties) are at risk from flooding. Included in this statistics is an average of 10,000 homes which are built on flood plains yearly, while 185,000 commercial properties are located in flood prone areas. These properties are valued at over $£ 801$ billion which accounts for 15.8 per cent of the value of total buildings and 2.2 per cent of total assets in the UK (Bhattacharya, et al., 2013). One in six residential and commercial properties, which form about 2.4 million in England are at risk of flooding from main rivers or the sea.

The commercial property sector plays an important role in the UK economy, both as a direct or indirect employer, a generator of output, and in providing other sectors including retailers, financial and business services, with a critical factor of production, that is, the location from which their business is done. It is estimated that the total output in the sector in 2011 was around $f 41 \mathrm{bn}$ which is equivalent to $3.2 \%$ of UK gross value added (GVA) and total employment of over 800,000 . The sector makes a substantial contribution to the exchequer, with an estimated contribution in VAT and PAYE income tax of approximately f6.5bn. Any disruption to the activities in this sector would be detrimental to the growth of the UK economy in total (Bhattacharya, et al., 2013). Sustainable Urban Drainage Systems (SuDs) are a system which could be used to protect commercial properties from flooding. SuDs are uniquely designed to mimic natural infiltration patterns, so that they can reduce the risk of flooding by reducing runoff volume and attenuation peak flows. Kirby (2005) described SuDs as more sustainable than conventional drainage methods because they are designed to manage flow rates, protect or enhance water quality and are sympathetic to the environmental setting and the needs of the local community by dealing with runoff close to where rain falls or attenuating flows and controlling discharges downstream.

However, the uptake of SuDs and the retrofit of SuDs has been restricted by a number of issues including, a lack of experience and trust in such schemes, and a lack of understanding of their 
wider benefits (Oladunjoye, et al., 2017; Malulu, 2016; Ossa-Moreno, 2017; Ellis, 2013; Lamond, 2016). There has been limited research on the retrofit of SuDs and there are no well established procedures for evaluating the feasibility, value or cost-effectiveness of doing this (Ossa-Moreno, 2017 and Alexander, et al., 2016). Lead (2018) revealed that 68\% of construction professionals felt there was a lack of understanding of SuDs among key decisionmakers. However, there remains growing interest in the introduction of this technology (Stovin, 2010) and stakeholders and researchers have sought to develop modalities on how to make SuDs more acceptable and relevant in the UK (Carboni, 2016). This study aims to help facilitate a deeper appreciation of the monetary and non-monetary value of SuDs retrofit with the development of a cost benefit analysis (CBA) model towards improving uptake and thereby improving flood risk mitigation in commercial properties in the UK. The results of this study will help to develop a better understanding of the longterm viability of SuDs retrofit and its monetary value, in order to encourage uptake by key decision makers involved in the development and redevelopment of buildings.

\subsection{SUSTAINABLE URBAN DRAINAGE SYSTEMS}

Sustainable urban drainage systems (SuDs) is a generic term that refers to various measures used to control the effect of surface water runoff in the environment (Locatelli, 2016). Booth and Charlesworth (2017) defined sustainable drainage as the management of rainwater which includes snow and other precipitation, with the aim of reducing damages caused by flooding events, improving the quality of water, the improvement and protection of the environment, the improvement and safety of the health of the residents and the process of ensuring the effective stability and durability of drainage systems. Baron and Petersen (2016) further described SuDs as an important contribution to urban climate change adaptation.

SuDs replicate the natural drainage processes of an area through the use of vegetation-based interventions such as swales, water gardens, and green roofs, which increase localised infiltration, attenuation and/or detention of stormwater. Hence, SuDs improves flood alleviation capacity in any community. SuDs are essential for the reduction in the quantity of surface water that flows off a surface and are useful for different purposes including reduction in runoff by, for example, the installation of green roofs or other SuDs which could result in savings in wastewater disposal (Wilkinson, and Dixon, 2016). The most well used SuDs are rainwater harvesting systems, green roofs, swales, rainwater beds and permeable surfaces as 
well as open drainage waterways and reservoirs for excess rainwater (Baron and Petersen, 2016). All these solutions aim to absorb, evaporate and/or channel rainwater so it does not end up in the sewage system.

\subsection{Retrofit of Sustainable Urban Drainage Systems}

SuDs retrofit is a storm water management process which is aimed at addressing urban water quality and the problems associated with flooding (Walsh, et al, 2016). Retrofit is used when SuDs are proposed for the replacement or augmentation of an existing drainage system (Smith, 2016). Examples of retrofitting SuDs can be seen in the installation of green roofs, the diversion of roof drainage from a combined sewer system into a garden soakaway, and the conveyance of road runoff via roadside swales into a pond sited in an area of open space (Ellis, 2013). These represent alternative ways of influencing the quality of the water downstream and the problems relating to it, thereby providing a more effective, resilient and sustainable approach. For SuDs to be acceptable, three core attributes are essential: economic viability, resilience and sustainability (Lead, 2018).

In considering the economic viability of SuDs retrofit, it is important that SuDs retrofit is affordable in costs and benefit for it to be accepted as a potential replacement for the existing drainage system. Fisher-Jeffes et al. (2011) identified that impacts such has aesthetics, economic value, rainwater harvesting, influences the choices made by individuals and organisations as it affects the cost and sale of properties. Ossa-Moreno et al. (2017) opined that for a SuDs retrofit installation to be economically feasible or viable, the wider benefits would need to be taken into account.

Resilience is multifaceted and is defined in different ways by various professionals. Proverbs et al., (2018) defines resilience as the ability of a system to return to its stable state after a momentary disturbance. Therefore, the acceptance of SuDs retrofit in terms of its resilience requires that the installation of SuDs retrofit would help to restore any flood affected area into a more attractive place.

According to Sieker et al. (2008), SuDs are known to be more adaptable and flexible than traditional solutions, allowing future modification to cope with climate and other changes in urban areas. Therefore, if SuDs retrofit can be incorporated into existing developed areas, the opportunities for delivering sustainable solutions that offer multiple benefits will be much greater. 


\subsection{The Implementation of the Retrofit of SuDs}

In this section, various benefits and barriers to the uptake of SuDs retrofit have been identified. The implication of the impact of these factors are further discussed.

\section{Processes of the implementation of the retrofit of SuDs}

A number of benefits that cut across various positive improvements in schemes and the lives of people have been identified. For example, Malulu (2016) found that a common SuDs intervention scheme entails the carrying out of works to rivers with the aim of increasing their capacity to carry flood flows. Friberg et al. (2016) identify a further scheme involving channel maintenance or enlarging the channel cross section and thereby increasing the flow of surface water by extending the capacity. The mitigation of the heat island effect and noise, the improvement in air and water quality and the provision of sites for recreation or urban amenities are various ways by which the ecosystem is sustained through SUDS retrofit (Demuzere et al., 2014; Ellis, 2013; Kazmierczak et al., 2010).

Other benefits of SuDs retrofit is in the reduced cost of infrastructure by the introduction of green infrastructure. Ellis (2013) argues that conventional drainage systems cannot provide the expected solution to any flood mitigation process but an extended approach based on the introduction of retrofit SuDs, in the likes of micro-and meso-vegetative SuDS systems into a wider green infrastructure(GI) framework, can effectively address on-site and catchment urban surface water issues. Foster et al. (2011), identified the importance of the aesthetic value of a building or location which is increased by the installation of SuDs retrofit by way of green infrastructure, creating habitat for wildlife, by constructing swales and other forms. Health improvements from the use of SuDs is also an important benefit to every citizen. Lamond et al. (2015) affirm the importance of an improved flood risk management system to manage the growing pressure of the effect of flooding events on the health of the occupants of any community. Greenough et al. (2001) address the health effects of flooding which are typically associated with disasters. These are direct morbidity and mortality and secondary or indirect health impacts. A direct impact includes an impaired public health infrastructure, reduced access to health care facilities, and psychological and social effects. While indirect effects could result in the alteration of ecologic systems which may result in land covers (i.e, grass, asphalt, trees etc) being damaged, and the abundance and distribution of disease- 
carrying insects, rodents and some other vectors. An improved health system through the application of SuDs retrofit helps to address these health issues.

Economically, the security of the reputation of a business is very important. In recent years, the importance of reputation has become increasingly apparent with the rising effect of damages which are caused by flood events. A good reputation for an organisation will inform the consumer's preference and external support for an organisation in critical times and enhance the value of an organisation in the market place (Epstein, 2018). Economic growth can also be stimulated by SuDs retrofit, through attractiveness of an area to new businesses, creation of jobs from the installation and maintenance of SuDs, and the improved productivity of workers when the environment is positively impacted by aesthetics, improved health conditions, improved air quality and many others (West et al., 2009; Kruger, 2014). Carpenter (2012) found that an aesthetically improved environment with the installation of SuDs can improve tourist attractions and recreation centres, with the aim of attracting visitors from both locally and internationally. Green infrastructure has been credited in the UK with significant impact in job creation (Chegut et al., 2014). Also in the United States, shoppers tend to stay longer when visits are made for business purposes, owing to the presence of green structures (Yi, 2014).

In addition, in projecting the cost of installing SuDs retrofit and the future effect on a community, most importantly when considering a value oriented structure, a conducive whole life costing (WLC) is guaranteed for a clearer understanding of the required costs. Lamond (2016) explains whole life costing as a methodology that gives a systematic economic consideration of all costs associated with SuDs retrofit. In considering this methodology, a number of factors are measured - finance, business costs and income from land sale, user costs. In order to deliver the best value for money, these factors are essential when measuring the economic implications in terms of the cost effectiveness of SuDs retrofit in a community. Despite the increased flooding events in the UK, the uptake of SuDs retrofit as a flood risk management measure is still largely being ignored (Ossa-Moreno et al., 2017). The lack of experience of, and trust in some of the approaches is a major setback for the implementation of SuDs retrofit (Backhaus et al., 2016). Convincing stakeholders about the implementation of a new scheme is difficult when consideration is given to failed flood risk management schemes (Kundzewicz et al., 2017). 
Flood management in England and Wales is currently seen differently to water supply and water quality management terms (Kangalawe, 2017). In Wales, Natural Resource Wales (NRW) provide an oversight role in relation to all flood and coastal risk management in Wales and are responsible for managing flooding from main rivers, reservoirs and the sea including the provision of technical advice and support. While in England, The Department for Environment, Food and Rural Affairs (Defra) is the policy lead for flood and coastal erosion risk management in England. These bodies have got their individual policies which differ in some ways and hinders the possibility of collaborating efforts and budgets across these regions through major solutions which are able to manage existing challenges in a cost effective way (Cousins 2017).

The responsibility for the cost of maintaining and implementing SuDs retrofit is also a major barrier (Ashley et al., 2010). Like all drainage systems, SuDs retrofit should be inspected and maintained. This will ensure efficient operation and prevention of future failures. However, the lack of understanding of the cost of maintenance and implementation of this relatively new scheme is exacerbating its uptake.

\subsection{COST BENEFIT ANALYSIS APPROACHES}

In approaching real life problems, a number of decision making tools have been developed such as Cost benefit analysis (CBA), cost-effectiveness analysis, cost-utility analysis, riskbenefit analysis, economic impact analysis, fiscal impact analysis, and social return on investment (SROI) analysis (Greco, et al, 2005; Snell 2011).

Cost effectiveness analysis (CEA) is an economic analysis tool, distinct from CBA which assigns value to the measure of effect. It compares relative costs and outcomes of different actions (Price, 2018). CEA is applied to planning and management of many types of organised activities and it is used in many aspects of life which includes the health sector where it may be inappropriate to monetize health effects. Campillo-Artero and Ortún (2016) defined CEA as a measure of health that developed countries use in making funding decisions, which is aimed at publicly funding health technologies that produce the greatest health gain at a given cost. CEA has faced some setbacks due to the fact that it reflects mistrust of the underlying methods or the motives of the parties conducting the analyses, or a desire on the part of many to deny or downplay the underlying problem of resource scarcity in health care due to the ethical difficulty in monetizing health effects. However, CEA is widely accepted as a useful tool for 
resource allocation. CEA is also not applicable in the context of this research,Brock (2004) opined that there are important ethical and value choices to be made in constructing and using CEA; these choices are not merely technical, empirical, or economic, but moral and value choices as well. These moral choices explains why it may be difficult to quantify outcomes of health issues and its suitability for a cost benefit analysis model.

Cost utility analysis (CUA) is similar to CEA, it is mostly used in pharma economics especially health technology assessments (HTA). It estimates the ratio between the cost of a healthrelated intervention and the benefit it produces in terms of the number of years lived in full health by the beneficiaries. CUA are estimates of health outcomes and costs of competing alternatives and is widely accepted as a useful tool for resource allocation. Health outcomes are commonly summarized as quality-adjusted life-years (QALY), which are a combination of quantity and quality of life (Kuntz, 2016). There are continuing controversies about the QALY unit, which is used to measure the outcome of the findings from CUA. One very important aspect of the CUA is the term 'quality'. Richardson (1994) identified the fact that there are varieties of meanings to the 'quality' aspect of CUA, with different scaling techniques and concepts which makes CUA inappropriate as an idea economic tool. A similar principle that governs the ethical and moral implication of using CEA in this research context is also applicable with CUA because of the difficulty associated with monetizing its outcomes.

Risk-benefit analysis (RBA) seeks to quantify the risk and benefits by employing the ratio of the risk of an action to its potential benefits (Guo, et al, 2010). RBA for a clinical trial is provisionally based on the preclinical phase of the medicinal product. The sponsorinvestigator team needs to evaluate the toxicological tests and results as well as submit the data to the competent health authorities, with a projection of all the possible risks for the proposed trial subjects (Fortwengel, 2011). This tool does not have the facility to determine the cost of a product which is required under the determination of the cost effectiveness of SuDs retrofit because it is not a financial based tool. This is therefore outside the scope of the research on the cost and benefit of the installation of the retrofit of SuDs.

Furthermore, the economic impact analysis (EIA) examines the effect of an event on the economy in a specific location, this ranges from a single neighbourhood to the entire globe. EIA measures changes in business revenue, profits, personal wages which can lead to the suggestion of policies and laws that could improve the economy. Drucker (2015) described EIA method as an analytical technique that is predicated on economic stability, yet commonly 
applied to situations that violate this condition with little consideration of the implications. EIA is basically a tool which is useful for the wider economy of a nation and in determining the political and economic stability.

Fiscal impact analysis (FIA) is a tool that is used to compare project or policy change, changes in governmental costs against changes in governmental revenue. Moore (2015) describes the FIA tool as a revenue-to-cost relationship which explains the implication of a proposed revenue to be generated from a new development in any location. This can either be positive or negative, depending on whether the revenue generated is greater or lower than the cost. For example, Town A is a major residential development project that requires new services and facilities such as fire and police protection, libraries, schools, parks, and others. At the same time, Town A will as a result of this project receive new revenues such as property tax revenues, local sales tax revenue, and other taxes and fees. FIA therefore compares the total expected costs to the total expected revenues to determine the net fiscal impact of the proposed development on Town A.

The CBA approach has been selected in this study in order to undertake an economic appraisal of the monetary and non-monetary benefits of the uptake of SuDS retrofit. The CBA approach suggests that any new initiative or investment decision should only be adopted if its expected benefits (political, social, environmental and moral) exceed its costs (Wildavsky, 2018).

Rotimi (2014) successfully applied the CBA concept to property level floodf adaptation (PLFRA) measures, incorporating a recognition of the intangible benefits. This provided a robust mechanism for decision making on investments in property level floor adaptation (PLFRA) measures by homeowners. This model was designed to advise homeowners of the potential benefits of investing in property level floor adaptation (PLFRA) measures. Another example can be seen in the analysis carried out on the report on the cost benefit analysis of Western Cape climate change response (Parmesan, 2006). The Western Cape Government (WCG) recognised the risks posed by climate change to its economy, population, ecosystems and infrastructure and sought for measures to mitigate its effect by the use of the CBA model. The use of the CBA model helped lead to a better and more informed implementation process of activities that are economically valuable in terms of reducing climate change risks.

The CBA tool enables a clear monetary comparison of the costs and benefits of the installation of SUDS, thereby facilitating the decision making process and providing an appreciation of the cost effectiveness of the range of alternative solutions. A unique feature in this study is the 
application of the Choice Modelling Method (CMM). The CMM Method is to be employed to elicit willingness to pay (WTP) values from property owners to obtain the non-monetary benefits of the installation of SuDS retrofit. The advantage of using CMM is that respondents are presented with various alternative descriptions of non-monetary benefits, differentiated by their attributes and levels, and are asked to rank the various alternatives, to rate them or to choose their most preferred (Hanley, et al., 2001). By including price/cost as one of the attributes of the non-monetary benefits, willingness to pay can be indirectly recovered from people's rankings, ratings or choices.

\subsection{EVALUATION OF THE COSTS AND BENEFITS OF SUDS RETROFIT}

One of the important recommendations from the Pitt (2008) review was to encourage property owners to take up the responsibility of reducing the effect of flood events on their properties by the uptake of available flood risk measures. Although the uptake of SuDs remains challenging owing to the complexity in its monetary and non-monetary benefits, there is continuous growth in public interest (Ossa-Moreno, 2017). The proposed CBA conceptual framework has taken into consideration the key components associated with the cost and benefits of SuDs retrofit and could help support further uptake.

\subsection{The Costs of SuDs Retrofit}

In the development of the CBA conceptual framework, the method for estimating additional costs of the measures adopted is to proceed stage-by-stage from the beginning to the end of the estimation activity. This method, whilst time consuming, tends to be the best because it outlines a detailed and more informed process in handling the breakdown of the costs of installing SuDs.

Figure 1 is a representation of the stages that a typical SuDs retrofit installation is expected to go through for the full costs (and benefits) to be determined. These stages include the preliminary stage, implementation stage and the maintenance stage.

According to Merz et al. (2004), in estimating the cost of flood adaptation measures, the ability to categorise the flood mitigation measures by building design and construction process in the 


\begin{abstract}
required order has the potential to lead to a better outcome. The decision to invest in SuDs as
\end{abstract} a retrofit is determined by the type of property and the level of impact flood events have had and will have on the property. Therefore, it is important to consider the impact of flood characteristics in this evaluation process.

According to Proverbs and Soetanto (2004), the damage caused by flood events on any property is a function of variables including flood characteristics such as the depth of flood water, velocity, history, duration, probability and the source of the flood. Among these characteristics, flood depth, duration, probability, history, velocity are essential because they play significant roles in the extent of damage experienced by any property. They also help to determine the additional costs before installation as a result of the extent of damage and the repair work required. 
Flood Characteristics

the probability

Costs from the installation of SuDS retrofit

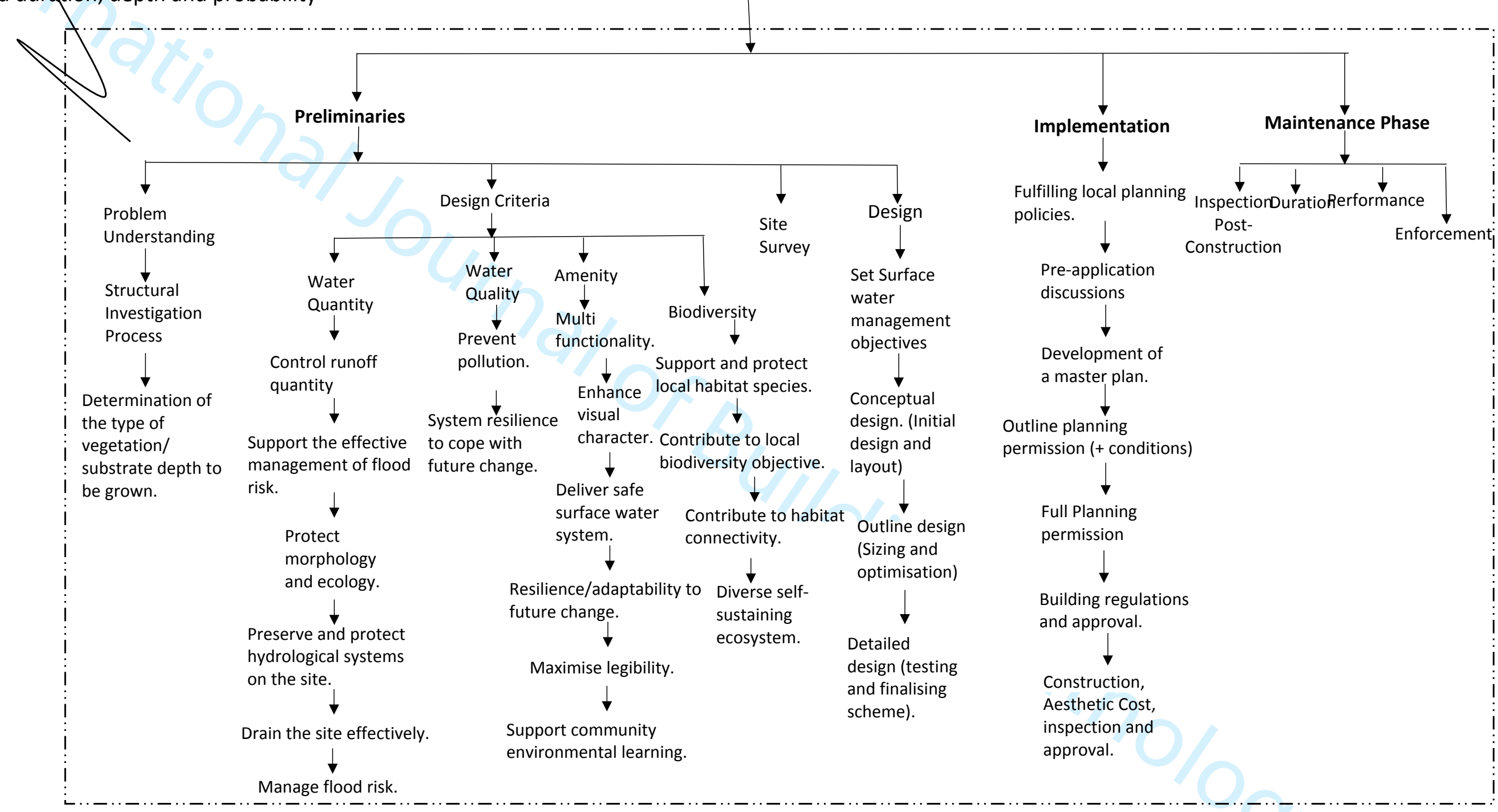

Figure 1: Cost parameter for the installation of SuDS retrofit 


\subsection{THE BENEFITS OF SUDS RETROFIT}

The uptake of SUDS as a retrofit could be of benefit to different stakeholders including property owners and users, insurance companies, flood management professionals and the government. The benefits of SuDS retrofit can be grouped into tangible benefits (Monetary) and intangible benefits (non-monetary) as shown in Figure 2.

To evaluate these benefits, several considerations needs to be involved, such as taking into account the benefits accruing to and the cost incurred by the property owner (PenningRowsell et al., 2005); selecting appropriate prices for evaluating the benefits and costs in monetary terms and adjusting the future prices of benefits to present values to make them comparable with the costs (Joseph, 2014). This means that despite the fact that the benefits and costs are from different sources, it is important that a systematic procedure is established to allow the proper evaluation of every parameter.

Bozman et al. (2015) described tangible benefits as quantifiable especially monetarily, these are identified as reduced cost of infrastructure, improved aesthetic value, reduction of surface water charges, flood risk reduction and improved market value of the property. The intangible benefits are subdivided into the benefits accrued by the property owner and the benefits accrued by the wider community. For the accrued benefits by the property owner, this includes rainwater harvesting, reduced post-flood recovery inconvenience, security of business reputation, reduced interruption to business activities, reduced cost of business assets and values, reduced insurance claim, increased property protection, reduced/elimination of property content evacuation and reduction in energy usage.

In terms of the benefits accrued by the wider community, this includes economic improvements, air and water quality, reduced loss of life, reduction/elimination of diseases, reduction /elimination of infections, reduction/elimination of muddy part ways, reduced loss of ecological and cultural values, reduction/elimination of depression, reduction/elimination of anxiety, reduction /elimination of stress, reduction of G.P. visits, habitat for wildlife.

Figure 2 shows the stages in evaluating the value of benefits that will accrue with the uptake of SuDS. These are in two forms, the actual market data for tangible benefits and the WTP values on the intangible benefits. This is important because the application of the concept of CBA requires that both the costs and benefits have to be in the same unit of measurement before any decision can be made on whether a project is cost-effective or not (Joseph, 2014). 


\section{Value of Benefits}

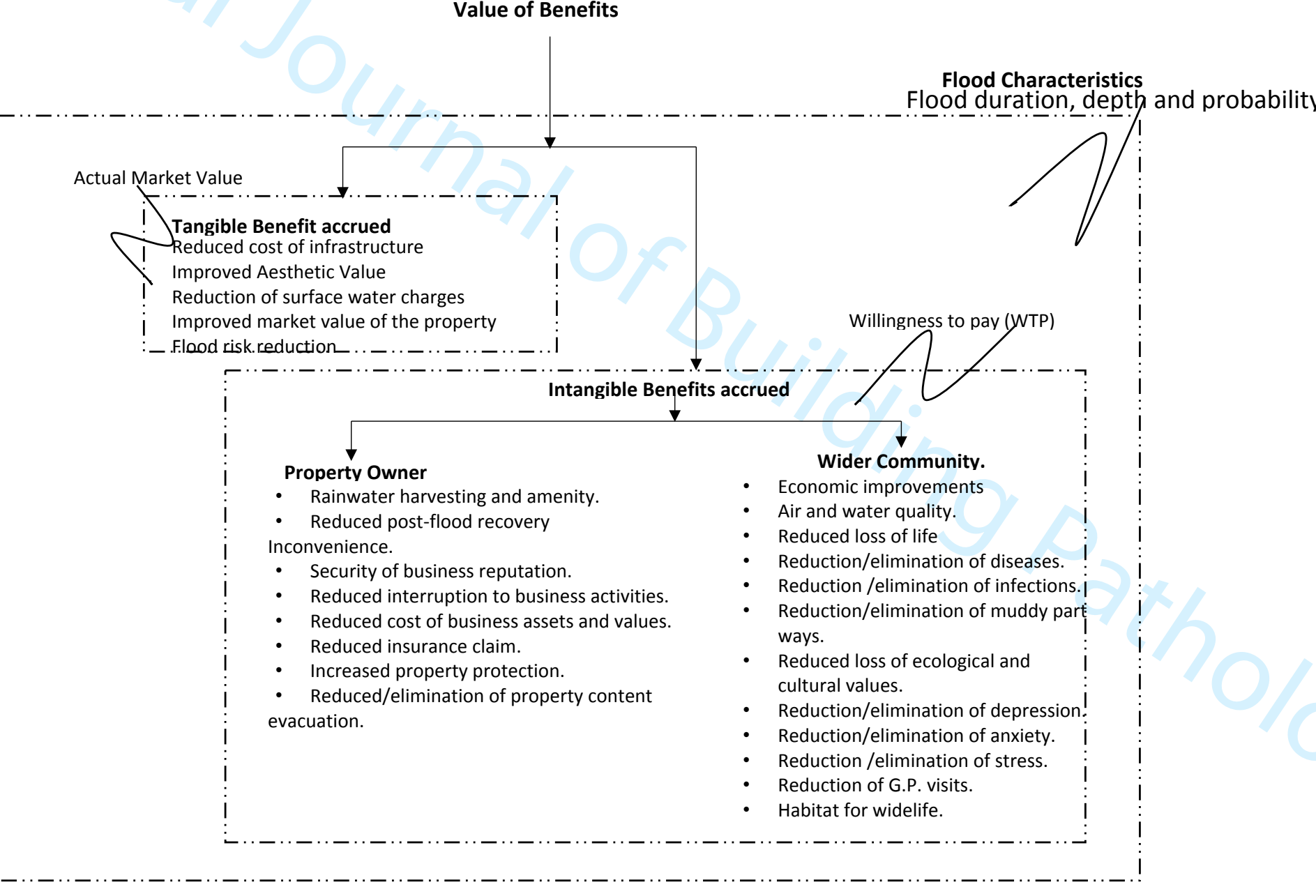

Figure 2: Value of Benefits 


\subsection{WILLINGNESS TO PAY (WTP)}

Intangible benefits by their subjective nature are difficult to quantify and are said to be more personal to the victim of a flood event (Joseph, 2014). This impact depends on the relationship of the individual to the loss or damage which had been experienced from the flood. Therefore, ignoring the intangible benefits of SuDS retrofit can lead to an incomplete understanding of the full benefits. Non-availability of locations where intangible benefits of flooding are being considered, makes its evaluation more difficult (Joseph, 2014; Markantonis and Meyer, 2011), this is why it is usually left out of the CBA appraisal for flood adaptation measures.

The intangible benefits of SuDS retrofit can be evaluated by using one of the stated preference methods (SPM) of valuation referred to as choice modelling method (CMM), this can be used to elicit WTP estimates from property owners.

\section{Choice modelling method (CMM)}

The CMM is a family of survey-based methodologies for modelling preference for different options of choices. CMM gives more detailed options to respondents enabling a more explicit understanding of their needs. With the choice modelling method, respondents are presented with various alternative descriptions of the intangible benefits with different levels of financial commitments which would then be ranked from most preferred till the less preferred. By including price as one of the rankings, willingness to pay can then be indirectly recovered from the ratings or choices (Snell, 2011).

In a typical CMM technique, individual preferences are uncovered in the survey by asking respondents to rank the options presented to them, to score them or to choose their most preferred. These different ways of measuring preferences correspond to different variants of the CMM approach. There are four major variants: choice experiments, contingent ranking, contingent rating and paired comparisons (Olazak, et al, 2018).

An example of the application of CMM in the context of this study is shown in Figure 3.

\begin{tabular}{|r|l|l|}
\hline $\begin{array}{l}\text { SuDs retrofit type (Green } \\
\text { Roof) }\end{array}$ & Intangible Benefit & WTP value (f) \\
\hline 1. 20years maintenance & Economic Improvement & 20,000 \\
2. 15years maintenance & & 15,000 \\
\hline
\end{tabular}




\section{Table 1: Example of the application of the CMM to intangible benefits.}

Table 1Figure 3: Example of the application of the CMM to intangible benefits.

\section{Discounting}

In considering the value of the benefits accrued from the installation of SuDS retrofit, it is important to apply a discount rate to both cost and benefits. Szekeres (2011) argues that it is useful to address how the discounting paradigm fares in the long run, especially as it affects climate change and environmental policy, to see if it suffers from any special limitations that need to be taken into account. Ackerman and Heinzerling (2001) described discounting as a tool used in CBA to compare the present costs and benefits and the implication for the future. This is the reduction in the value of future costs or benefits at a pre-specified rate, which depends on its temporal distance from a common time.

Given the value of money, a pound is worth more today than it would be worth tomorrow. Therefore, discounting is the primary factor used in pricing a stream of tomorrow's cash flow. Very often, decisions have to be made about whether to incur costs in the present, in return for benefits in the future, as in the case of investing in SuDS retrofit. Every investment requires this type of decision at one point or the other.

Since individuals and organisations have their preference as it relates to receiving benefits or incurring costs, time preferences also have to be accounted for through the process called discounting. The advantage of discounting is that it enforces consistency and it makes the assumptions explicit (Charness, et al, 2013).

In presenting the costs and benefits of SuDS retrofit in monetary terms, CBA follows standard economic practice in discounting future benefits and converting them to their equivalent value today, or present value. In the Economist view, when the time span is long and different generations are required to be involved in the costs and benefits of a particular project, the analogy to an individual investment decision breaks down (Keynes, 2018). Ackerman (2001) 

therefore suggested that when setting a discount rate for a project, it must be set to a very low level, so that an enhanced benefit is generated.

\subsection{Flood Probability}

One major factor in determining the cost effectiveness of SuDS retrofit is flood probability (flood return period). Destro et al. (2018) described it as the estimate of the likelihood of the occurrence of a flood event. It is a key determining factor in the installation of SuDS retrofit, as it affects the accrued benefits. A study by Thurston et al. (2008) determined that a flood resistance measure could be said to be worth an economical value for properties with a 50 year return period. However, properties that experience flooding events more than once in every ten years, the benefits outweigh the up-front investment. Also, Joseph et al. (2014) found that the adoption of resilience measures will be more economical for properties which are located in areas with up to 25 years return period. However, properties that experience flooding events more than once in every five years, the benefits are said to outweigh the upfront investment. Therefore, in considering the accrued benefits from repeat flooding in high risk areas, flood probability (flood return period) is an important variable which should be included in the CBA conceptual model.

\subsection{THE CONCEPTUAL FRAMEWORK}

Figure 4 represents the CBA framework for comparing the costs and benefits of SuDs retrofit in commercial properties. This CBA framework gives a detailed description of the monetary and non-monetary value of the installation of SuDs retrofit in a commercial property. Oladunjoye et al. (2017) identify this as a gap that as resulted in a reluctance towards the uptake of SuDs retrofit to mitigate flood risks, hence the need for a detailed framework that will give a robust understanding of the monetary values.

The framework is represented by a pivoted depiction representing the implications of the impact costs and the benefits accrued from a typical SuDs retrofit. Stovin (2013) and Lamond et al. (2014) opined that when considering the decision for the uptake of an element like SuDs retrofit, it is important that if the cost of installing SuDS retrofit is less than the benefit, then investment in it is advised but if it is otherwise, it is not advisable to go ahead with its uptake. 
In a typical CBA model, it is important that costs and benefits are well defined. Snell (2011) described CBA as a formal technique adopted for clear, systematic and rational decision making especially when faced with complex alternatives or uncertain data. Hence a detailed CBA model will make it easy for clarity and a rational decision to be attained. Although CBA is a well-established tool, its application in this context is quite unique. In this framework, in a bid to derive a robust outcome, consideration was given to the involvement of indirect property users in terms of the benefits accrued from the installation of SuDs retrofit.

The framework is divided into two parts representing firstly, the details of the costs of installing a typical SuDs retrofit for a commercial property and secondly, representing details of the accrued benefits. The CBA conceptual framework is developed by introducing required elements of the costs versus the tangible and intangible benefits as it affects commercial properties and reflects the hypothesised relationship between costs and benefits of a typical SuDs retrofit installation. The costs and benefits of the SuDs retrofit are linked together to produce a CBA conceptual framework which incorporates all necessary parameters.

A clear and well detailed process of installing a typical SuDs retrofit has been employed, to form the framework. This framework represents a contribution to the study of SuDs retrofit in the context of commercial property. In terms of the benefits accrued, these are considered in the context of both direct and indirect users of a commercial property. This is important because consideration is needed to be given to both the property owner and other users of the property such as customers, employees and suppliers.

Included in the framework are the flood characteristics which have influence on the outcome of the costs of installation and also the benefits. Flood duration, depth, velocity, probability and history are vital determinants in the determination of the outcome of installing SuDs retrofit. Soetanto, et al, (2004) opined that the damage caused by any disaster is highly dependent on the scale and nature of that disaster. In this context, the damage cause to a commercial property is dependent on the flood characteristics. 


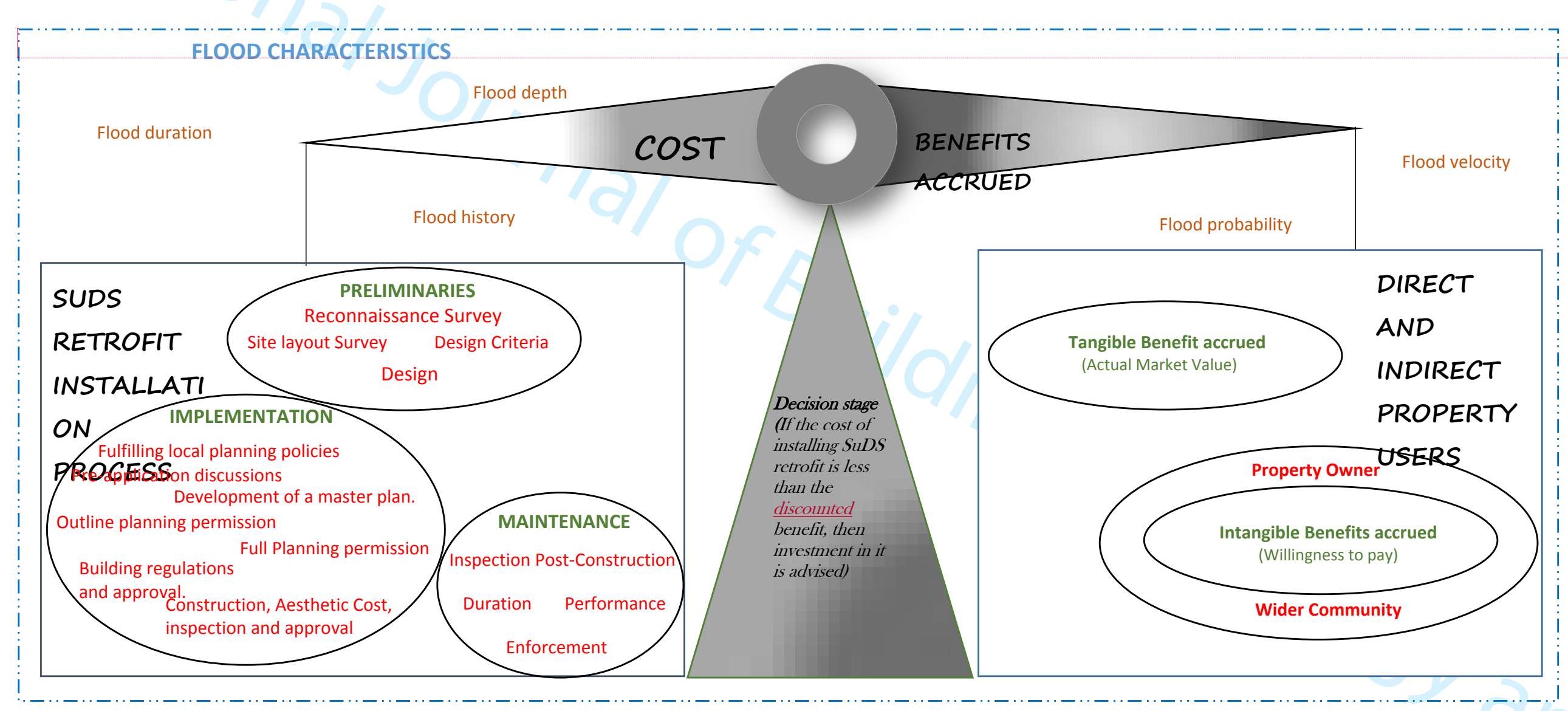

Figure 4: CBA Conceptual Framework for comparing the costs and benefits of suds retrofit in commercial properties 


\subsection{CONCLUSIONS}

The development of a CBA conceptual framework for the costs and benefits of SuDs retrofit has been discussed and presented. This framework highlights the essential elements of the costs and benefits of SuDs retrofit which need to be examined in the context of commercial properties. The CBA framework provides an in depth means of assessing the actual cost and benefits of the installation of SuDs retrofit. By combining the relevant elements in each section of the framework, the full costs and benefits of retrofitting SuDs can be established. This would help in the decision-making process when faced with choosing to invest in any type of SuDs retrofit.

The conceptual framework presented gives the much needed understanding about the cost effectiveness and benefits of the installation of the retrofit of SuDs which is previously lacking in the literature. The framework draws on the various approaches used in estimating costs and benefits of SuDs retrofit which will assist decision makers and end users in deciding how best to reduce the impacts of flooding.

A full understanding of the costs and benefits of retrofitting SuDs will help to inform better decision making in choosing the most appropriate and cost effective means of retrofitting SuDs for any given location. The proposed model is expected to be used by flood risk management professionals, property professionals and commercial property owners of the potential benefits of investing in the installation of SuDS. This study will help develop our understanding of the full costs and benefits accrued from the retrofit of SuDs and so lead to an increase in uptake. Also, details about the benefits accrued by indirect users of the commercial property will inform a robust understanding of the advantage that these set of users will derive from the uptake of SuDs retrofit. The model developed here is specifically for commercial properties but many of the principles applied would be equally relevant to other types of property.

However, one major challenge with this research is with quantifying the intangible accrued benefits from installing SuDs retrofit. Putting a value to these parameters are very important but difficult for most professionals to accomplish. Quillin (2010) described intangible benefits as hidden jewels that do exit and need to be accepted as valid. However, being able to validate this parameters stands as a major difficulty. 


\section{References}

Ackerman, F., \& Heinzerling, L. (2001). Pricing the priceless: Cost-benefit analysis of environmental protection. U. Pa. L. Rev., 150, 1553.

Alexander, M., Priest, S.J., Micou, P., Tapsell, S.M., Green, C.H., Parker, D.J. and Homewood, S., (2016). Analysing and evaluating flood risk governance in England-enhancing societal resilience through comprehensive and aligned flood risk governance arrangements.

Agwuele, A. ed., (2013). Development, Modernism and Modernity in Africa. Routledge.

Armstrong, J.T., 2010. Extensive green roof design in the City of Cape Town: barriers and opportunities for developing a green industry (Doctoral dissertation, University of Cape Town).

Armstrong, M. and Taylor, S., 2014. Armstrong's handbook of human resource management practice. Kogan Page Publishers.

Ashley, R.M., Walker, A.L., D’Arcy, B., Wilson, S., Illman, S., Shaffer, P., Woods-Ballard, P. and Chatfield, C., 2015. UK sustainable drainage systems: past, present and future. In Proceedings of ICE-Civil Engineering (Vol. 168, No. 3, pp. 125-130). Thomas Telford.

Assaf, S.A. and Al-Hejji, S., (2006). Causes of delay in large construction projects. International journal of project management, 24(4), pp.349-357.

Backhaus, K., Erichson, B., Plinke, W., \& Weiber, R. (2016). Multivariate analysemethoden. Springer Berlin Heidelberg.

Baron, N. and Petersen, L.K., (2016). Understanding Controversies in Urban Climate Change Adaptation. A case study of the role of homeowners in the process of climate change adaptation in Copenhagen. Nordic Journal of Science and Technology, 3(2), pp. 4-13.

Bhattacharya, N., Lamond, J., Proverbs, D. and Hammond, F., 2013. Development of conceptual framework for understanding vulnerability of commercial property values towards flooding. International Journal of Disaster Resilience in the Built Environment, 4(3), pp. 334351. 
Blevins, R.L., Lal, R., Doran, J.W., Langdale, G.W. and Frye, W.W., 2018. Conservation tillage for erosion control and soil quality. In Advances in soil and water conservation (pp. 51-68). Routledge.

Booth, C., and Charlesworth, S., (2017). Sustainable Surface Water Management: A hand book for SuDS. Wiley Blackwell, p3.Campillo-Artero, C., \& Ortún, V. (2016). Cost-effectiveness analysis: Why and how. Revista Española De Cardiología (English Edition), 69(4), 370-373. doi:10.1016/j.rec.2016.01.012

Bozman, C. S., Friesner, D., McPherson, M. Q., \& Chase, N. M. (2015). Intangible and tangible value: brand equity benefits associated with collegiate athletics. International Journal of Sports Marketing and Sponsorship, 16(4), 22-45.

Brock, D. (2004). Ethical issues in the use of cost effectiveness analysis for the prioritization of health resources. In Handbook of bioethics (pp. 353-380). Springer, Dordrecht.

Carboni, D., Gluhak, A., McCann, J.A. and Beach, T.H., (2016). Contextualising Water Use in Residential Settings: A Survey of Non-Intrusive Techniques and Approaches. Sensors, 16(5), pp. 738.

Charness, G., Gneezy, U., \& Imas, A. (2013). Experimental methods: Eliciting risk preferences. Journal of Economic Behavior \& Organization, 87, 43-51.

Chegut, A., Eichholtz, P., \& Kok, N. (2014). Supply, demand and the value of green buildings. Urban Studies, 51(1), 22-43.

Chofreh, A. G., Goni, F. A., \& Klemeš, J. J. (2018). Evaluation of a framework for sustainable Enterprise Resource Planning systems implementation. Journal of Cleaner Production, 190, 778-786.

Cousins, R. D. (2017). The Jeffreys-Lindley paradox and discovery criteria in high energy physics. Synthese, 194(2), 395-432.

Destro, E., Amponsah, W., Nikolopoulos, E.I., Marchi, L., Marra, F., Zoccatelli, D. and Borga, M., (2018). Coupled prediction of flash flood response and debris flow occurrence: application on an alpine extreme flood event. Journal of Hydrology. 


\section{Ellis, J.B., (2013). Sustainable surface water management and green infrastructure in UK urban} catchment planning. Journal of Environmental Planning and Management, 56(1), pp.24-41.

Epstein, M.J., 2018. Making sustainability work: Best practices in managing and measuring corporate social, environmental and economic impacts. Routledge

Fisher-Jeffes, Lloyd \& Armitage, Neil. (2011). A simple economic model for the comparison of SUDS and conventional drainage systems in South Africa.

Forman, R.T., Sperling, D., Bissonette, J.A., Clevenger, A.P., Cutshall, C.D., Dale, V.H., Fahrig, L., France, R.L., Heanue, K., Goldman, C.R. and Jones, J., (2003). Road ecology: science and solutions. Island press.

Fortwengel, G. (2011). Risk-Benefit Analysis. In Guide for Investigator Initiated Trials (pp. 1-3). Karger Publishers.

Foster, J., Lowe, A. and Winkelman, S., 2011. The value of green infrastructure for urban climate adaptation. Center for Clean Air Policy, 750, pp.1-52.

Green, C., 2010. Towards sustainable flood risk management. International Journal of Disaster Risk Science, 1(1), pp.33-43.

Greenough, G., McGeehin, M., Bernard, S.M., Trtanj, J., Riad, J. and Engelberg, D., (2001). The potential impacts of climate variability and change on health impacts of extreme weather events in the United States. Environmental health perspectives, 109(Suppl 2), p.191.

Guo, J. J., Pandey, S., Doyle, J., Bian, B., Lis, Y., \& Raisch, D. W. (2010). A review of quantitative risk-benefit methodologies for assessing drug safety and efficacy-report of the ISPOR riskbenefit management working group. Value in Health, 13(5), 657-666.

Hanley, N., Mourato, S., \& Wright, R. E. (2001). Choice modelling approaches: a superior alternative for environmental valuatioin?. Journal of economic surveys, 15(3), 435-462.

Joseph R., (2014). Development of a comprehensive systematic quantification of the costs and benefits ( $\mathrm{CB}$ ) of property level flood risk adaptation measures in England (Doctoral dissertation, University of the West of England). 
Kangalawe, R. Y. (2017). Climate change impacts on water resource management and community livelihoods in the southern highlands of Tanzania. Climate and Development, 9(3), 191-201.

Kazmierczak, A., \& Carter, J. (2010). Adaptation to climate change using green and blue infrastructure. A database of case studies.

Keynes, J. M. (2018). The general theory of employment, interest, and money. Springer.

Kirby, A., (2005), June. SuDS- innovation or a tried and tested practice?. In Proceedings of the Institution of Civil Engineers-Municipal Engineer (Vol. 158, No. 2, pp. 115-122). London: Published for the Institution of Civil Engineers by Thomas Telford Services, c1992-.

Kruger, W. J. (2014). The integration of spatial-and infrastructure planning at municipal level (Doctoral dissertation).

Kundzewicz, Z. W., Krysanova, V., Dankers, R., Hirabayashi, Y., Kanae, S., Hattermann, F. F., ... \& Matczak, P. (2017). Differences in flood hazard projections in Europe-their causes and consequences for decision making. Hydrological Sciences Journal, 62(1), 1-14.

Kuntz, K. M., ScD. (2016). Decision modeling for cost-utility analysis. Value in Health, 19(6), 700-701. doi:10.1016/j.jval.2016.06.003

Lamond, J.E., (2016). Whole Life Costing and Multiple Benefits of Sustainable Drainage. Sustainable Surface Water Management: A Handbook for SUDS, p.235.

Landon, J.R., 2014. Booker tropical soil manual: a handbook for soil survey and agricultural land evaluation in the tropics and subtropics. Routledge.

Lazzarini, L., 2018. The role of planning in shaping better urban-rural relationships in Bristol City Region. Land Use Policy, 71, pp.311-319.

Lead, C., (2018). Urban Planning and Urban Design. Climate Change and Cities: Second Assessment Report of the Urban Climate Change Research Network, p.139.

Locatelli, L., (2016). Modelling the impact of Water Sensitive Urban Design technologies on the urban water cycle. 
Malulu, I.C., (2016). Opportunities for integrating Sustainable urban Drainage Systems (SuDS) in informal settlements as part of stormwater management (Doctoral dissertation, Stellenbosch: Stellenbosch University).

Markantonis, V. and Meyer, V., (2011). Valuating the intangible effects of natural hazards: a review and evaluation of the cost-assessment methods. In European Society for Ecological Economics conference.

Merz, B., Kreibich, H., Thieken, A., \& Schmidtke, R. (2004). Estimation uncertainty of direct monetary flood damage to buildings. Natural Hazards and Earth System Science, 4(1), 153163.

Moore, P. (2015). Fiscal Impact Analysis. In Encyclopedia of Public Administration and Public Policy-5 Volume Set (pp. 1-5). Routledge.

O'BRIEN, C.D., 2015. Sustainable drainage system (SUDS) ponds in Inverness, UK and the favourable conservation status of amphibians. Urban Ecosystems, 18(1), pp. 321-331.

$\begin{array}{lllll}\text { Oladunjoye, O., Proverbs, } & \text { D., Collins, } & \text { B., } & \text { (2017). }\end{array}$ https://www.researchgate.net/publication/319718484_the_barriers_and_opportunities_to_ the_retrofit_of_sustainable_urban_drainage_systems_suds_towards_improving_flood_risk_ mitigation_in_urban_areas_in_the_uk [accessed Apr 10 2018].

Olazak, C., \& Mach-Król, M. (2018). A Conceptual Framework for Assessing an Organization's Readiness to Adopt Big Data. Sustainability, 10(10), 3734.

Ossa-Moreno, J., Smith, K.M. and Mijic, A., (2017). Economic analysis of wider benefits to facilitate SuDS uptake in London, UK. Sustainable Cities and Society, 28, pp.411-419.

Parmesan, C. (2006). Ecological and evolutionary responses to recent climate change. Annu. Rev. Ecol. Evol. Syst., 37, 637-669.

Penning-Rowsell, E., Johnson, C., Tunstall, S., Tapsell, S., Morris, J., Chatterton, J., \& Green, C. (2005). The benefits of flood and coastal risk management: a handbook of assessment techniques. ISBN 1904750516.

Price, R., 2018. Cost-effectiveness of disaster risk reduction and adaptation to climate change. 
Proverbs, David \& Xiao, Hong \& Oladokun, Victor \& Adedeji, Taiwo. (2018). Towards a conceptual framework for property level flood resilience. International Journal of Safety and Security Engineering. 8. 10.2495/SAFE-V8-N4-493-504.

Richardson, J. (1994). Cost utility analysis: what should be measured?. Social science and medicine, 39(1), 7-22.

Robichaud, L.B. and Anantatmula, V.S., 2010. Greening project management practices for sustainable construction. Journal of Management in Engineering, 27(1), pp.48-57.

Robinson, D.J., 2018. Assessing Green Infrastructure Needs in Hampton Roads, Virginia and Identifying the Role of Virginia Cooperative Extension (Doctoral dissertation, Virginia Tech).

Rushton, A., Croucher, P. and Baker, P., 2014. The handbook of logistics and distribution management: Understanding the supply chain. Kogan Page Publishers.

Shrivastava, A.K., Yadav, S., Yadav, L.S., Khan, S., Khan, A.R. and Sharma, S., 2018. Global Warming Issues-Need for Sustainable Drainage System in Urban Areas-Green Construction Technologies. In Energy and Environment (pp. 15-28). Springer, Singapore.

Sieker, H., Helm, B., Krebs, P., Schlottmann, P. and Tränker, J., 2008. Flexibility-a planning criterion for stormwater management. In 11th International Conference on Urban Drainage. Edingburgh.

Smith, R.E., 2010. Prefab architecture: A guide to modular design and construction. John Wiley \& Sons.

Smith, J.O.M.K.M. and Mijic, A., (2016). Economic analysis of wider benefits to facilitate SuDS. Environment, 33(1), pp.70-84.

Snell, M., (2011). Cost-benefit analysis: A practical guide. 2nd Edition. London: Thomas Telford.

Soetanto, R., \& Proverbs, D. G. (2004). Impact of flood characteristics on damage caused to UK domestic properties: the perceptions of building surveyors. Structural Survey, 22(2), 95104. 


\begin{abstract}
Stovin, V., Swan, A. and Moore, S., (2007). Retrofit SuDS for urban water quality enhancement. Dept. of Civil and Structural Engineering, Univ. of Sheffield, Sheffield, UK.

Stovin, V., (2010). The potential of green roofs to manage urban stormwater. Water and Environment Journal, 24(3), pp.192-199SZEKERES, S. (2011). discounting in cost-benefit analysis. Society and Economy, 33(2), 361-385. doi:10.1556/SocEc.33.2011.2.7
\end{abstract}

Thurston, N., Finlinson, B, Breakspear, R., Williams, N., Shaw, J. and Chatterton, J. (2008), Developing the Evidence Base for Flood Resistance and Resilience Joint Defra/EA Flood and Coastal Erosion Risk Management R\&D, DEFRA, London.

Vargas Renzi, F., (2018). BIM Application in Construction Management (Master's thesis, Universitat Politècnica de Catalunya).

Vincent, S.U., Radhakrishnan, M., Hayde, L. and Pathirana, A., (2017). Enhancing the Economic Value of Large Investments in Sustainable Drainage Systems (SuDS) through Inclusion of Ecosystems Services Benefits. Water, 9(11), p.841.

Walsh, C., Burke, S., Glendinning, S. and Dawson, R., (2016). Alternative business models for flood risk management infrastructure. In E3S Web of Conferences (Vol. 7, p. 20015). EDP Sciences.

Weimer, D.L. and Vining, A.R., (2017). Policy analysis: Concepts and practice. Taylor \& Francis. Wildavsky, A., (2018). Economy and environment rationality and ritual. In The art and craft of policy analysis (pp. 193-214). Palgrave Macmillan, Cham.

Wilkinson, S.J. and Dixon, T. eds., 2016. Green Roof Retrofit: building urban resilience. John Wiley \& Sons.

Winsemius, H.C., Jongman, B., Veldkamp, T.I., Hallegatte, S., Bangalore, M. and Ward, P.J., (2018). Disaster risk, climate change, and poverty: Assessing the global exposure of poor people to floods and droughts. Environment and Development Economics, pp.1-21. 
Woods Ballard, B., Wilson, S., Udale-Clarke, H., Illman, S., Scott, T., Ashley, R. and Kellagher, R., (2015). The SuDS Manual, C753, CIRIA, London, UK. ISBN 978-0-86017-760-9. http://www. susdrain. org/resources/SuDS_Manual. html.

Yi, S., Wang, X., Qin, Y., Xiang, B., \& Ding, Y. (2014). Responses of alpine grassland on QinghaiTibetan plateau to climate warming and permafrost degradation: a modeling perspective. Environmental Research Letters, 9(7), 074014. 